\title{
1 Lateral dimension and amino-functionalization on the balance to assess \\ 2 the single-cell toxicity of graphene on fifteen immune cell types
}

3

4 Laura Fusco ${ }^{\text {a\#}}$, Marco Orecchioni ${ }^{\text {b,c\#}, \text { Giacomo Reina }}{ }^{\mathrm{d}}$, Valentina Bordoni ${ }^{\mathrm{c}}$, Claudia Fuoco ${ }^{\mathrm{e}}$, Cansu 5 Gurcan $^{\mathrm{f}, \mathrm{g}}$, Shi Guo ${ }^{\mathrm{d}}$, Martina Zoccheddu ${ }^{\mathrm{c}}$, Federica Collino ${ }^{\mathrm{a}}$, Barbara Zavan ${ }^{\mathrm{a}, \mathrm{h}, \mathrm{i}}$, Emanuele Treossi ${ }^{\mathrm{j}}$, 6 Acelya Yilmazer ${ }^{\mathrm{f}, \mathrm{g}}$, Vincenzo Palermo $^{\mathrm{j}}$, Alberto Bianco $^{\mathrm{d} *}$, Lucia Gemma Delogu $^{\mathrm{a}, \mathrm{c}, *}$

7

8

9

10

11

12

Authors:

aDepartment of Biomedical Sciences, University of Padua, Padua, Italy.

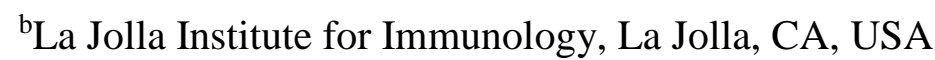

${ }^{c}$ Department of Chemistry and Pharmacy, University of Sassari, Sassari, Italy.

${ }^{\mathrm{d}}$ CNRS, Immunology, Immunopathology and Therapeutic Chemistry, University of Strasbourg, ISIS, Strasbourg, France.

e'Department of Biology, University of Rome Tor Vergata, Rome, Italy.

fDepartment of Biomedical Engineering, Ankara University, Ankara, Turkey.

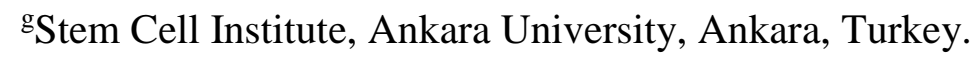

hDepartment of Medical Sciences, University of Ferrara, Ferrara, Italy.

${ }^{\mathrm{i}}$ Maria Cecilia Hospital, GVM Care \& Research, Ravenna, Italy.

jISOF-CNR, Bologna, Italy.

\section{\#Equal contribution}

*Corresponding author

\section{Correspondence:}

Dr. Lucia Gemma Delogu, Email: luciagemma.delogu@unipd.it

Dr. Alberto Bianco, Email: a.bianco@ibmc-cnrs.unistra.fr 


\section{Abstract}

26 Given the wide variety of potential applications of graphene oxide (GO), its consequent release into the 27 environment poses serious concerns on its safety. The future production and exploitation of graphene in potential of single-cell mass cytometry (CyTOF) to dissect by high-dimensionality the specific immunological effects of nanomaterials, represents a turning point in nanotoxicology. It helps us to identify the safe graphene in terms of physical-chemical properties and therefore to direct its future safe production.

Here we present a high-dimensional study to evaluate two historically indicated as key parameters for the safe exploitation: functionalization and dimension. The role of lateral dimension and the aminofunctionalization of GO on their immune impact were here evaluated as synergistic players. To this end, we dissected the effects of GO, characterized by a large or small lateral size (GO $1.32 \mu \mathrm{m}$ and GO 0.13 $\mu \mathrm{m}$, respectively), and its amino-functionalized counterpart $\left(\mathrm{GONH}_{2} 1.32 \mu \mathrm{m}\right.$ and $\mathrm{GONH}_{2} 0.13 \mu \mathrm{m}$, respectively) on fifteen cell types of human primary peripheral blood mononuclear cells (PBMCs).

We describe how the smallest later size not only evokes pronounced toxicity on the pool of PBMCs compared to larger GOs but also towards the distinct immune cell subpopulations, in particular on nonclassical monocytes, plasmacytoid dendritic cells (pDCs), natural killer cells (NKs) and B cells. The amino-functionalization was able to improve the biocompatibility of classical and non-classical monocytes, pDCs, NKs, and B cells. Detailed single-cell analysis further revealed a complex interaction of all GOs with the immune cells, and in particular monocyte subpopulations, with different potency depending on their physicochemical properties. Overall, by high-dimensional profiling, our study demonstrates that the lateral dimension is an important factor modulating immune cells and specifically monocyte activation, but a proper surface functionalization is the dominant characteristic in its immune effects. In particular, the amino-functionalization can critically modify graphene impact dampening the immune cell activation. Our study can serve as a guide for the future broad production and use of graphene in our everyday life.

Keywords: carbon materials, 2D materials, single-cell, biocompatibility, cytotoxicity, safety 


\section{Introduction}

Graphene-related materials (GRMs) have gained increasing interest and expectation in the scientific community due to their unique combination of physicochemical properties.[1-12] In particular, graphene oxide (GO), the oxidized form of graphene, represents the most largely explored GRM, as a promising nanotool in the field of nanoelectronics, energy technology, bio-sensoristics, and biomedicine.[13, 14] An ever-growing GO-enhanced products are already commercially available, such as touch screens, batteries, clothes, sports manufacturing, and sensors, and many more will follow.[15]

Given the wide variety of potential biomedical or technological applications of GO and the material introduction into the market, its consequent release into the environment during the industrial life-cycle poses serious concerns on its safety following human exposure.[16, 17] We see now how plastics impact the environment and therefore human health, what if we will have the same scenario for graphene? A deep understanding of graphene toxicity for its specific chemical-physical parameters is today urgent. In vivo biodistribution studies have shown that, after intra-tracheal instillation, GO nanosheets were mainly found in the lungs, but interestingly they could also be detected in the blood, liver, and kidneys, suggesting, besides secondary swallowing of inhaled material, a possible direct translocation of GO from the lungs to the systemic circulation.[18] Similarly, GO was found in blood and main organs after oral administration due to its absorption in the gastrointestinal tract and the subsequent secondary distribution to the organs through the bloodstream.[19] These findings are in agreement with the observation that GO can pass through lung capillaries after intravenous administration.[20] Overall, these studies suggested that GO can cross physiological barriers and easily reach the bloodstream. Consequently, the nanomaterial will immediately be recognized by circulating immune cells into the blood, the body's first line of defense against exogenous agents. Therefore, the understanding of the sophisticated interactions between GO and the complex immune system is critical to promote sustainable applications of this technology in the future.

Such interplay can be modulated by the specific nanomaterial physicochemical properties, as we recently introduced by the nanoimmunity-by-design concept.[21] Indeed, GRMs are a heterogeneous class of materials characterized by a variety of different properties, which could modulate their reactivity and interactions with the immune cells. This makes the assessment of their health and safety risks a challenging field.[22] In this context, during the last decade, research efforts have been directed towards understanding how the physicochemical parameters of nanomaterials and nanoparticles affect their interaction with biological systems, from single cells to whole organisms.[23-25] For example, various 
studies suggest that shape, size and functionalization of nanoparticles can be designed to target specific cellular uptake mechanisms, biodistribution patterns, and pharmacokinetics.[26]

Therefore, the appropriate understanding of the structure-activity relationship is an important concern in nanomaterial safety-related research. In the attempt to address this issue, GRMs have been rationally classified based on three main fundamental properties: number of layers, average lateral dimension, and atomic carbon/oxygen ratio.[27] Thanks to such classification system, it is possible to compare, for certain parameters, the findings of different studies investigating the biological effects of wellcharacterized materials. However, to avoid generalizations about capabilities, limitations, and safety of graphene and its derivatives, there is still an urgent need for the development of a dynamic system for the rational classification of GRMs, based not only on their different physicochemical characteristics but also on their biological effects.[27, 28] The insufficient implementation of high-dimensional deep phenotyping technologies in the field is holding us back from the exploration of this delicate aspect.

In the attempt to address these issues, we have recently proven single-cell mass cytometry (CyTOF) to be a powerful strategy to uncover the immune impact of GRMs.[29] Thanks to the use of metal-tagged probes with minimal spectra overlap and background cellular signal, this technology has the unique ability of simultaneously measuring a wide number of cellular parameters at single-cell resolution, enabling high-dimensional cytometry analysis that would not be possible otherwise. The possibility of multiplex analysis of cell types, activation status and soluble inflammatory mediators represents a turning point in the field of nanotoxicology.

Despite the evidence that the material characteristics can modulate their impact on the immune cell, no study has evaluated the role and possible synergistic effects of different GO parameters at the same time on distinct immune subpopulations at the single-cell level, by varying different physicochemical properties simultaneously.

The extensive literature on GRMs has evidenced that the lateral size is an important parameter to take into account on their potential toxicological effects [30]. In our previous manuscripts, we revealed the specific immune impact of the amino-functionalization [29], and the lateral size of GO. However, we only explored a single GO parameter - either the amino-functionalization or the lateral size - at a time, while the combination of these physicochemical properties and how they can lead to a different GO impact on human health, were not explored yet. 
115 Hence, herein we aimed to fill the gap concerning the simultaneous role of two most critical 116 physicochemical parameters on its immune effects, namely the lateral dimension and the chemical 117 functionalization. Which is the parameter responsible of a biological effect: the amino groups or the 118 lateral size? Among them, which one is dominating? Do the combination lead to a synergistic biological 119 effect? By addressing these questions at the single-cell level we aimed at: i) understanding the structure120 activity relationship in the context of human health and safety, and ii) avoiding generalizations about the 121 capabilities and limitations of GO. As a proof of concept, we studied here the influence of lateral size 122 and of amino-functionalization of GO. We explored the possible synergistic effects of these key 123 properties at the same time, investigating the single-cell immune impact of four GOs: GO $1.32 \mu \mathrm{m}$ and $124 \mathrm{GO} 0.13 \mu \mathrm{m}$, characterized by a similar oxidation state but differing for their lateral size (1.32 and 0.13 $125 \mu \mathrm{m}$, respectively), and their amino-functionalized counterparts $\left(\mathrm{GONH}_{2} 1.32 \mu \mathrm{m}\right.$ and $\mathrm{GONH}_{2} 0.13 \mu \mathrm{m}$, 126 respectively)."

127 A comprehensive analysis was performed on human primary peripheral blood mononuclear cells (PBMCs), which closely mimic the in vivo scenario of first interactions between nanomaterials and the immune system. After evaluating the effects of the materials on immune cell apoptosis and necrosis, their ability to interact with the distinct immune cell subpopulations was dissected at the single-cell level applying CyTOF technology, allowing to determine the specific impact on 15 immune cell types in terms of cell viability, activation and cytokine secretion. Overall, by single cell mass cytometry on human primary cells, the present study reveals the combined, synergic effects of two critical physical parameters analyzed together, at the same time on same samples: the amino-functionalization and the lateral dimension.

\section{2. Materials and methods}




\subsection{Chemicals and materials preparation}

140

141

142

143

144

145

146

147

148

149

150

151

152

153

154

155

156

157

158

159

160

161

162

163

164

165

166

167

2,2'-(Ethylenedioxy)bis(ethylamine) (TEG) was purchased from Sigma-Aldrich, purified water was prepared using a Millipore filter system MilliQ ${ }^{\circledR}$ and free endotoxin Polisseur Biopak®. All reagents of analytical grade for ex vivo experiments were purchased from Sigma-Aldrich (Milan, Italy), if not otherwise specified. GO $1.32 \mu \mathrm{m}$ and GO $0.13 \mu \mathrm{m}$ used in this study were obtained as we previously reported.[31, 32] In details, monolayer GO with an average lateral size of $1.32 \mu \mathrm{m}(\mathrm{GO} 1.32 \mu \mathrm{m})$ was obtained by chemical exfoliation of graphite flakes, using a modified Hummers' method. A second batch of samples with average lateral size of $0.13 \mu \mathrm{m}$ was obtained by sonication of GO $1.32 \mu \mathrm{m}$ for $26 \mathrm{~h}$. For the preparation of GO- $\mathrm{NH}_{2}$ samples, $10 \mathrm{mg}$ of each GO were dispersed in $9 \mathrm{ml}$ of water. Subsequently, $1 \mathrm{mg}$ of TEG dissolved in $1 \mathrm{ml}$ of water was added dropwise to the $\mathrm{GO}$ dispersion at room temperature under stirring. The reaction mixture was stirred for three days at room temperature. Subsequently, the free amine excess was removed through dialysis against water (Spectra/Por® dialysis membrane MWCO 12000-14000 Da) for three days and the final conjugates were stored at $4{ }^{\circ} \mathrm{C}$ in dark conditions. Part of the products were lyophilized for characterizations.

\subsection{Material characterizations}

Transmission electron microscopy (TEM). TEM analyses were performed on a Hitachi H600 with an accelerating voltage of $75 \mathrm{kV}$. The samples were dispersed in water, PBS or cell culture medium (RPMI 1640 with $10 \% \mathrm{FBS}$ ) at a concentration of about $16 \mu \mathrm{g} / \mathrm{mL}$ and the suspensions were sonicated for 10 min. Ten microliters of the suspensions were drop-casted onto a copper grid (Formvar film $300 \mathrm{Mesh}$, $\mathrm{Cu}$ from Electron Microscopy Sciences) and left for evaporation under ambient conditions. To remove the salts from PBS and cell medium, the grids were deposit onto $10 \mathrm{~mL}$ water for 20 min and left for evaporation under ambient conditions.

Atomic force microscopy measurements (AFM). AFM were prepared by spin coating GO solutions on freshly cleaned $\mathrm{SiO}_{2} / \mathrm{Si}$ substrates. AFM measurements have been performed in tapping mode using a Bruker MultiMode 8, equipped with probe cantilevers model RTESPA-300 (material: 0.01-0.025 $\Omega \mathrm{cm}$ $\mathrm{Sb}(\mathrm{n})$-doped Si, f0: $300 \mathrm{kHz}, \mathrm{k}: 40 \mathrm{~N} / \mathrm{m}$, from Bruker). By statistical analysis on several images, corresponding to a total area of $\sim 100 \mu \mathrm{m}^{2}$, we estimated that the average single layer thickness is $1.1 \pm 0.1$ $\mathrm{nm}$ for GO $0.13 \mu \mathrm{m}$ and $1.3 \pm 0.2 \mathrm{~nm}$ for $\mathrm{GONH}_{2} 0.13$. 
Thermogravimetric analysis (TGA) was performed on a TGA1 (Mettler Toledo) apparatus from $30{ }^{\circ} \mathrm{C}$ to $900{ }^{\circ} \mathrm{C}$ with a ramp of $10{ }^{\circ} \mathrm{C} \mathrm{min}^{-1}$ under $\mathrm{N}_{2}$ using a flow rate of $50 \mathrm{~mL} \mathrm{~min}{ }^{-1}$ and platinum pans. XPS analyses were performed on a Thermo Scientific K-Alpha X-ray photoelectron spectrometer with a basic chamber pressure of $10^{-8}-10^{-9}$ bar with an anode using $\mathrm{Al} \mathrm{K \alpha}$ radiation $(\mathrm{h} v=1486.6 \mathrm{eV}) . \mathrm{C}(1 \mathrm{~s})$ photoelectron binding energy was set at $284.5 \pm 0.2 \mathrm{eV}$ and used as reference for calibrating the other peak positions. The samples were analyzed as powder. Spot size of $400 \mu \mathrm{m}$ was used. The survey spectra are average of 10 scans with a pass energy of $200.00 \mathrm{eV}$ and a step size of $1 \mathrm{eV}$. The high-resolution spectra are an average of 10 scans with a pass energy of $50 \mathrm{eV}$ and a step size of $0.1 \mathrm{eV}$. An ion gun was turned on during analysis. For each sample the analysis was repeated three times.

Zeta potential data. Stock solutions (at $1 \mathrm{mg} / \mathrm{mL}$ ) of the four materials were diluted in milli- ${ }^{\circledR}$ water to about $0.1 \mathrm{mg} / \mathrm{mL}$. All tests were performed three times at $25^{\circ} \mathrm{C}$ with $120 \mathrm{~s}$ equilibration time using a Malvern Zetasizer Nano ZS (Malvern Instruments).

Dynamic light scattering (DLS). Stock solutions (at $1 \mathrm{mg} / \mathrm{mL}$ ) of the four materials were diluted in milli$\mathrm{Q}^{\circledR}$ water, PBS or cell medium to about $0.01 \mathrm{mg} / \mathrm{mL}$. All tests were performed three times at $25^{\circ} \mathrm{C}$ with 20 s equilibration time using a Malvern Zetasizer Nano ZS (Malvern Instruments).

Reactive oxygen species (ROS) test. Stock solutions (at $1 \mathrm{mM}$ ) of dihydrorhodamine 123 (DHR123) in DMSO were diluted in milli- ${ }^{\circledR}$ water to about $200 \mathrm{nM}$. Twenty $\mu \mathrm{L}$ of stock solutions (at $1 \mathrm{mg} / \mathrm{mL}$ ) of the GO materials were added to $2 \mathrm{~mL}$ DHR123 test solution and the fluorescence was collected under excitation at $485 \mathrm{~nm}$ via a Fluorolog FL3-22(Horiba Jobin Yvon) spectrometer using a swig xenon 450W lamp. A Fenton reaction was performed as a positive control. Twenty $\mu \mathrm{L}$ stock solutions (at $0.1 \mathrm{mM}$ ) of the $\mathrm{FeSO}_{4} \cdot 7 \mathrm{H}_{2} \mathrm{O}$ was added to $2 \mathrm{~mL}$ DHR 123 test solution followed by $200 \mu \mathrm{L}$ of $\mathrm{H}_{2} \mathrm{O}_{2}$. The fluorescence was collected immediately ( $<1 \mathrm{~min}$ ) and 10 min after adding $\mathrm{H}_{2} \mathrm{O}_{2}$.

All materials were analyzed for endotoxin presence before the assays with immune cells (data not shown), as we previously reported within the Graphene Flagship EU project [33].

\subsection{Isolation of human PBMCs}

Fresh human blood stabilized with ethylenediaminetetraacetic acid (EDTA) was obtained from informed donors (25-50 years old). The Ethics Committee of the University of Sassari reviewed and approved all the protocols performed. All the experiments were carried out in accordance with the approved guidelines. PBMCs were isolated using Ficoll-Plaque ${ }^{\mathrm{TM}}$ PLUS (GE Healthcare) high density gradient 
197

198

199

200

201

202

203

204

205

206

207

208

209

210

211

212

213

214

215

216

217

218

219

220

221

222

223

224

225

226

centrifugation at 1:1 ratio and cultured in RPMI 1640 medium with the addition of $10 \%$ inactivated fetal bovine serum, $1 \%$ penicillin $10000 \mathrm{IU} / \mathrm{mL}$ and streptomycin $10 \mathrm{mg} / \mathrm{mL}$.

\subsection{Viability and apoptosis assay}

Cell viability was evaluated as percentage of apoptotic and necrotic cells by Annexin V (AnnexV; BD Bioscience, San Josè, CA, USA) and 7-aminoactinomycin D (7-AAD; BD Bioscience, San Josè, CA, USA) staining, respectively. Briefly, PBMCs were seeded at a density of $5 \times 10^{5}$ cells/well in 24-well plates and treated with 5 and $50 \mu \mathrm{g} / \mathrm{mL}$ of GO $1.32 \mu \mathrm{m}$, GO 0.13 or $\mathrm{GONH}_{2} 1.32 \mu \mathrm{m}, \mathrm{GONH}_{2} 0.13 \mu \mathrm{m}$ for 24 and $48 \mathrm{~h}$ or left untreated (Ctrl). Ethanol $70 \%$ (v/v) was used as positive control. All experiments were performed in triplicate with PBMCs derived from three different donors. Cells were analyzed by flow cytometry (FACS Canto II, BD Biosciences, Mountain View, CA, USA) and 25,000 events were counted.

\subsection{Release of TNF- $\alpha$}

PBMCs treated with GO $1.32 \mu \mathrm{m}$, GO $0.13 \mu \mathrm{m}, \mathrm{GONH}_{2} 1.32 \mu \mathrm{m}$, or $\mathrm{GONH}_{2} 0.13 \mu \mathrm{m}(50 \mu \mathrm{g} / \mathrm{ml})$ for 24 h. LPS $(2 \mu \mathrm{g} / \mathrm{mL})$ was added as positive control. Cell culture supernatants were collected and the secretion of TNF- $\alpha$ was analyzed by an ELISA Kit, according to the manufacturer's instructions (Millipore, Billerica, MA)

\subsection{Expression of CD25 cell activation marker}

PBMCs were seeded at a density of $1 \times 10^{6}$ cells/well in 12 -well plates and treated with 5 and $50 \mu \mathrm{g} / \mathrm{mL}$ of GO $1.32 \mu \mathrm{m}$ or GO $0.13 \mu \mathrm{m}$ for $24 \mathrm{~h}$ or left untreated (Ctrl). Subsequently, PBMCs were stained with specific fluorescent mAbs to identify the CD25 immune activation marker (APC-conjugated anti-CD25, 2A3 clone, BD-Bioscience Mountain View, CA, USA). LPS (2 $\mu \mathrm{g} / \mathrm{mL}$; Sigma-Aldrich, St. Louis, Missouri, USA) was used as positive control. Cell fluorescence was measured by flow cytometry (FACS CANTO II BD Bioscience) and 50,000 to 100,000 events were collected.

\subsection{Single-cell mass cytometry}

Single-cell mass cytometry analysis was performed using purified PBMCs obtained as described above. PBMCs were seeded at a density of $4 \times 10^{6}$ cells/well in 6-well plates and treated with $50 \mu \mathrm{g} / \mathrm{mL}$ of GO 
$1.32 \mu \mathrm{m}$, GO 0.13 or $\mathrm{GONH}_{2} 1.32 \mu \mathrm{m}, \mathrm{GONH}_{2} 0.13 \mu \mathrm{m}$ for $24 \mathrm{~h}$. LPS $(2 \mu \mathrm{g} / \mathrm{mL}$; Sigma - Aldrich, Missouri, USA) and untreated cells were used as positive and negative controls, respectively. For the detection of cytokines, brefeldin A $(10 \mu \mathrm{g} / \mathrm{mL})$ was added $5 \mathrm{~h}$ before the incubation ended. After the incubation, cells were harvested and washed with phosphate-buffered saline (PBS). Before the staining, cells were incubated with Cisplatin-194Pt to a final concentration of $1 \mu \mathrm{M}$ for $5 \mathrm{~min}$, and subsequently washed with a sterile solution of PBS, EDTA 0.5 M and 5\% of fetal calf serum (FCS). Cells were then combined using Cell-ID 20-Plex Pd Barcoding Kit (Fluidigm, CA, USA) and stained with Maxpar Human Peripheral Blood Phenotyping and Human Intracellular Cytokine I Panel Kits (Fluidigm, CA, USA) following the manufacturer staining protocol for cell surface and cytoplasmic/secreted markers. For the monocytes-oriented experiments, the Maxpar Human Peripheral Blood Phenotyping and Human Intracellular Cytokine I Panel Kits (Fluidigm, CA, USA) were implemented and modified with CD25 (Sm149), CD80 (Dy161), and IL-6 (Sm147). Briefly, cells were harvested and suspended in $50 \mu \mathrm{L}$ of Maxpar Cell Staining Buffer into $15 \mathrm{~mL}$ polystyrene tubes for each sample. The surface marker antibody cocktail (dilution of 1:100 for each antibody) was added to each tube (final volume $100 \mu 1$ ). Samples were mixed and incubated for $30 \mathrm{~min}$ at RT. After incubation, the samples were washed twice with Maxpar Cell Staining Buffer. Cells were then fixed by adding $1 \mathrm{~mL}$ of Maxpar Fix and Perm Buffer to each tube and incubated for $10 \mathrm{~min}$. After incubation, the cells were washed twice with Maxpar Fix and Perm Buffer and centrifuged for 5 min at $800 \times \mathrm{g}$. Cells were then suspended in $50 \mu \mathrm{L}$ of Maxpar Fix and Perm Buffer and incubated as described above with cytoplasmic/secreted antibody cocktail (dilution of 1:100 for each antibody final volume $100 \mu \mathrm{l}$ ). Afterwards, the cells were washed twice with Maxpar Cell Staining Buffer and incubated with Cell-ID Intercalator-Ir solution at the final concentration of $125 \mathrm{nM}$ into Maxpar Fix and Perm Buffer for 5 min. Each sample was then washed twice with Maxpar Cell Staining Buffer and suspended with $2 \mathrm{~mL}$ of ultrapure water. Before the data acquisition, each sample was filtered into $5 \mathrm{~mL}$ round bottom polystyrene tubes with a $30 \mu \mathrm{m}$ cell strainer cap to remove possible cell clusters or aggregates. Data were analyzed using mass cytometry platform CyTOF2 (Fluidigm Corporation, CA, USA).

\subsection{Gating strategy and statistical analysis methods applied}

The CyTOF data analysis was performed according to the methods described by Orecchioni M et al.[29] and Bendall et al.[34] Summarizing, normalized, background subtracted FCS files were uploaded into 
257

258

259

260

261

262

263

264

265

266

267

268

269

270

271

272

273

274

275

276

277

278

279

280

281

282

283

284

285

286

Cytobank for the analysis. Cell events were gated excluding doublets, cell debris, and dead cells by means of Cell-ID Intercalator-Ir and LD. Specific PBMC subsets and subpopulations were identified using the following strategy: $\mathrm{T}$ cells (CD45+ CD19- CD3+), T helper (CD45+ CD3+ CD4+), $\mathrm{T}$ cytotoxic (CD45+ $\mathrm{CD} 3+\mathrm{CD} 8+)$, $\mathrm{T}$ naive (CD45RA+ CD27+ CD38- HLADR-), T effector (CD45RA+ CD27- CD38HLADR-), and activated (CD38+ HLADR+), B cells (CD45+ CD3- CD19+), NK cells (CD45+ CD3CD19- CD20- CD14- HLADR- CD38+ CD16+), Classical monocytes (CD45+ CD3- CD19- CD20HLADR $+\mathrm{CD} 14+)$, Intermediate monocytes (CD45+ CD3- CD19- CD20- HLADR+ CD14dim CD16+) Non classical monocytes (CD45+ CD3- CD19- CD20- HLADR+ CD14- CD16+), mDC $(\mathrm{CD} 45+\mathrm{CD} 3-\mathrm{CD} 19-\mathrm{CD} 20-\mathrm{CD} 14-\mathrm{HLA}-\mathrm{DR}+\mathrm{CD} 11 \mathrm{c}+\mathrm{CD} 123-)$, and pDC $(\mathrm{CD} 45+\mathrm{CD} 3-\mathrm{CD} 19-$ CD20- CD14- HLADR + CD11c- CD123+). Cytobank allowed the realization of the heat map visualization comparing marker signal intensity of the treated populations with mean marker intensity vs. the untreated control. viSNE tool was exploited. viSNE, a cytometry analysis tool implemented in Cytobank, uses t-stochastic neighbor embedding (t-SNE) portraying single cells in a two- or threedimensional plot, on the basis of their relationships. Nine cell surface markers were used to draw the viSNE map for the Maxar PBMCs staining: CD3, CD4, CD8a, CD11c, CD14, CD16, CD19, CD20, CD123, and HLADR. The specific ViSNE on myeloid populations were performed on the gated CD3CD19/CD20- CD11c+ HLADR+ events; to construct the ViSNE map CD14, CD16, HLADR and CD11c were applied. The cytokine data analysis was performed exploiting viSNE tool. Plots showing the expression intensity of the analyzed cytokines (IFN $\gamma$, IL-2, IL-4, IL-5, IL17a, IL-6, MIP1 $\beta$ and TNF $\alpha$ ) and heat maps of mean marker expression ratio for all cytokines were realized.

\subsection{Statistical analysis}

Data analyses were performed using Prism GraphPad software. Statistics for experiments were performed using a One-Way and Two-way ANOVA with Dunnet's multiple comparison test. Test T Student were used when appropriate. In all cases, * was used for $p<0.05$, ** for $p<0.01$, *** for $p<$ 0.001 , and $* * * *$ for $p<0.0001$. Values were expressed as mean \pm SD. Flow cytometry data were analyzed with FACS Diva software (BD-Bioscience Mountain View, CA, USA) and FlowJo software, (BD-Bioscience Mountain View, CA, USA).

\section{Results}


287

288

289

290

291

292

293

294

295

296

297

298

299

300

301

302

303

304

305

306

307

308

309

310

311

312

313

314

315

316

317

\subsection{Characterization of GO conjugates}

We selected two different monolayered GO characterized by a similar oxidation state, but with different lateral size: $1.32 \pm 1.02 \mu \mathrm{m}$ and $0.13 \pm 0.08 \mu \mathrm{m}$ (GO $1.32 \mu \mathrm{m}$ and GO $0.13 \mu \mathrm{m}$, respectively).[31] GO $1.32 \mu \mathrm{m}$ and GO $0.13 \mu \mathrm{m}$ were the functionalized with TEG diamine obtaining $\mathrm{GONH}_{2} 1.32 \mu \mathrm{m}$ and $\mathrm{GONH}_{2} 0.13 \mu \mathrm{m}$. TEG molecules were grafted onto GO surface via epoxide opening reaction as already reported by us.[35]. These four samples were analyzed by TEM and AFM to evidence their structural characteristics. In particular, TEM images of the GOs before and after their functionalization were first collected in water (Figure S1). We also decided to observe these materials in PBS and in cell culture medium containing $10 \%$ of serum to evidence the possible aggregation in salt- and serum-reach solutions constituting these media. There are no evident changes in the sizes and aggregation state of the four different conjugates. As expected, we have a slightly higher later size in the case on GO modified with the amino groups and after dispersion in PBS and cell culture medium. As the thickness of the layers is not influenced by the later size, we decided to perform AFM analyses only on GO $0.13 \mu \mathrm{m}$ and $\mathrm{GONH}_{2}$ $0.13 \mu \mathrm{m}$ nanosheets (Figure S2). A higher thickness was observed for the functionalized sample $(\sim 1.3$ $\mathrm{nm})$ compared to GO $0.13 \mu \mathrm{m}(\sim 1.1 \mathrm{~nm})$ due to the presence of the TEG molecules grafted onto the surface of GO. Moreover, $\mathrm{GONH}_{2} 0.13 \mu \mathrm{m}$ could be observed as overlapped flakes, while GO $0.13 \mu \mathrm{m}$ appeared as separated flakes or touching each other only in very small regions. This observation can be related to a stronger flake-to-flake interaction in the case of $\mathrm{GONH}_{2} 0.13 \mu \mathrm{m}$ as in the case of TEM images.

The samples were then further characterized TGA. GO $1.32 \mu \mathrm{m}$ and GO $0.13 \mu \mathrm{m}$ show typical profile with two steps degradation (Figure S3, black lines).[35] The mass loss below $100{ }^{\circ} \mathrm{C}$ is associated to the desorption of water, subsequently deoxygenation of the functional groups occurs at around $200{ }^{\circ} \mathrm{C}$. TEG functionalization changes the TGA profile of both $\mathrm{GONH}_{2} 1.32 \mu \mathrm{m}$ and $\mathrm{GONH}_{2} 0.13 \mu \mathrm{m}$ (Figure S3, blue lines). The higher degradation steps present also in the starting materials are shifted at lower temperature (about $170^{\circ} \mathrm{C}$ ). Moreover, an extra degradation step is present at about $330{ }^{\circ} \mathrm{C}$. This changing of profile is associated with the formation of secondary amine onto the GO surface that are thermally less stable than the starting oxygenated groups. Grafting of amines has been also confirmed by XPS characterization (Figure S4). In particular, starting GO $1.32 \mu \mathrm{m}$ and GO $0.13 \mu \mathrm{m}$ showed a negligible presence of $\mathrm{N}$ onto their surface (Table 1). After functionalization, $\mathrm{N}$ atomic \% raised to 3.1 and $3.4 \%$ for $\mathrm{GONH}_{2} 1.32 \mu \mathrm{m}$ and $\mathrm{GONH}_{2} 0.13 \mu \mathrm{m}$, respectively. Interestingly, $\mathrm{GONH}_{2} 1.32 \mu \mathrm{m}$ and $\mathrm{GONH}_{2}$ $0.13 \mu \mathrm{m}$ showed similar functionalization grade (Table 1). The N1s high resolution spectra of $\mathrm{GONH}_{2}$ 

to the amine groups $\left(\mathrm{C}-\mathrm{NH}-\mathrm{C} / \mathrm{C}-\mathrm{NH}_{2}\right)$ and to the protonated amines $\left(\mathrm{C}-\mathrm{NH}_{3}{ }^{+}\right)$, respectively $($Figure S5). Similarly, a new C-N component appeared in the $\mathrm{C} 1 \mathrm{~s}$ high resolution spectra of $\mathrm{GONH}_{2} 1.32 \mu \mathrm{m}$ and $\mathrm{GONH}_{2} 0.13$ after deconvolution, which is negligible in pristine GO $1.32 \mu \mathrm{m}$ and GO $0.13 \mu \mathrm{m}$ (Figure S5 and Table S1).

On the basis of these characterizations, the main physicochemical properties (i.e., average lateral size, carbon/oxygen ratio, and percentage of nitrogen) for each of the four GOs have been summarized in

\section{Table 1.}

Table 1. Physicochemical characteristics of the four GO.

\begin{tabular}{|l|l|l|l|}
\hline Name & \multicolumn{1}{l}{$\begin{array}{l}\text { Lateral } \\
\text { Size }\end{array}$} & C/O & N atomic \% \\
\hline GO 1.32 $\boldsymbol{\mu m}$ & $1.32 \mu \mathrm{m}$ & 1.96 & $0.41 \pm 0.05$ \\
\hline GO 0.13 $\boldsymbol{~} \mathbf{m}$ & $0.13 \mu \mathrm{m}$ & 1.89 & $0.43 \pm 0.08$ \\
\hline $\mathbf{G O N H}_{\mathbf{2}} \mathbf{1 . 3 2} \boldsymbol{\mu m}$ & $1.32 \mu \mathrm{m}$ & 1.96 & $3.1 \pm 0.1$ \\
\hline $\mathbf{G O N H}_{\mathbf{2}} \mathbf{0 . 1 3} \boldsymbol{\mu m}$ & $0.13 \mu \mathrm{m}$ & 1.89 & $3.4 \pm 0.2$ \\
\hline
\end{tabular}

Dynamic light scattering (DLS) was then applied to qualitatively evaluate the changes in the hydrodynamic sizes of the four GOs before and after their functionalization in water, PBS and cell culture medium (Figure S6). Again, we could observe a higher later dimension for the GO samples with the amino groups after dispersion in PBS and in cell medium. These data should not be considered quantitative but they help to evidence the behaviour of graphene materials in different biological environment. The results obtained by DLS and TEM measurements in cell culture medium allowed us to make some hypotheses on the effect of protein corona generated around our four GO materials. The corona formation can exert different effects on the materials, e.g. changing their later dimension and moderating their cytotoxicity. Coronation can also disturb the colloidal stability of the formulations because of the formation of large agglomerates, consequently influencing the cell uptake [36]. However, not significant changes and little aggregation was observed in our dispersions.

The colloidal stability was then assessed by the measurement of zeta potential in water. Zeta potential data confirmed the presence of amino groups onto GO surface (Figure S7). GO $1.32 \mu \mathrm{m}$ and GO 0.13 $\mu \mathrm{m}$ possess a typical value around $-50 \mathrm{mV}$. After the reaction with TEG-diamine, both $\mathrm{GONH}_{2} 1.32 \mu \mathrm{m}$ and $\mathrm{GONH}_{2} 0.13 \mu \mathrm{m}$ showed a higher zeta potential compared with GO precursors, confirming also the success of the functionalization. Finally, as GO sample with the smaller later size was prepared by bath sonication during $26 \mathrm{~h}$, we verified the presence of reactive radicals on the two samples. The presence of 
reactive oxygen species (ROS) of GO $1.32 \mu \mathrm{m}$ and GO $0.13 \mu \mathrm{m}$ dispersed in water was assessed

347

348

349

350

351

352

353

354

355

356

357

358

359

360

361

362

363

364

365

366

367

368

369

370

371

372

373

374

following the fluorescence changes of dihydrorhodamine 123 (DHR123) using a spectrofluorimeter (Figure S8). A Fenton reaction was firstly performed using $\mathrm{Fe}^{2+}$ and $\mathrm{H}_{2} \mathrm{O}_{2}$ as a positive control. The nonfluorescent DHR123 is oxidized to fluorescent rhodamine 123 leading to a significant increase of photoluminescence within $1 \mathrm{~min}$. The increase of fluorescence was instead negligible in both GO samples after 10 min revealing the absence of ROS. This experiment allowed also to evidence that the sonication of GO $1.32 \mu \mathrm{m}$ to prepare the small GO $0.13 \mu \mathrm{m}$ nanosheets did not generate additional ROS.

\subsection{Impact of lateral size and functionalization of GOs on human peripheral blood mononuclear cells}

Initially, to evaluate the impact of the different lateral size and functionalization on the immune system, human PBMCs were treated with 5 and $50 \mu \mathrm{g} / \mathrm{mL}$ of GO $1.32 \mu \mathrm{m}$, GO $0.13 \mu \mathrm{m}, \mathrm{GONH}_{2} 1.32 \mu \mathrm{m}$ or $\mathrm{GONH}_{2} 0.13 \mu \mathrm{m}$ for 24 and $48 \mathrm{~h}$, or left untreated (Ctrl), and the effects on cell viability were analyzed by flow cytometry. Ethanol $70 \%(\mathrm{v} / \mathrm{v})$ was used as a positive control.

As shown in Figure 1A, displaying histograms related to the percentage of apoptotic cells evaluated by AnnexV, the materials did not induce any significant effect up to $48 \mathrm{~h}$. The impact on PBMC was then evaluated in terms of necrosis using the 7-AAD staining, allowing the detection of late apoptotic and necrotic cells. As reported in Figure 1B, a significant effect was observed for GO $1.32 \mu \mathrm{m}$ and GO 0.13 $\mu \mathrm{m}$, already starting from $24 \mathrm{~h}$ exposure. However, while the material characterized by the largest lateral dimension (GO $1.32 \mu \mathrm{m})$ was able to induce a significant $(* p<0.05)$ toxic effect only at the highest concentration tested $(26.1 \%$ of death cells at $50 \mu \mathrm{g} / \mathrm{mL})$, the effect induced by the smallest material (GO $0.13 \mu \mathrm{m})$ was significant $(* * p<0.01)$ at all concentrations tested $(32.0$ and $36.8 \%$ of death cells at 5 and $50 \mu \mathrm{g} / \mathrm{mL}$, respectively). Increasing exposure time up to $48 \mathrm{~h}$, a time-dependent effect was also observed confirming a different potency depending on the lateral dimension, GO $0.13 \mu \mathrm{m}$ being more toxic than GO $1.32 \mu \mathrm{m}$ at both 5 (24.9 and 37.0\% of death cells induced by GO $1.32 \mu \mathrm{m}$ and GO $0.13 \mu \mathrm{m}$, respectively) and $50 \mu \mathrm{g} / \mathrm{mL}(32.4$ and $39.0 \%$ of death cells induced by GO $1.32 \mu \mathrm{m}$ and GO $0.13 \mu \mathrm{m}$, respectively). Intriguingly, the amino functionalization dramatically improved the biocompatibility of the materials. In fact, no significant toxic effects were observed after treatment with $\mathrm{GONH}_{2} 1.32 \mu \mathrm{m}$ or $\mathrm{GONH}_{2} 0.13 \mu \mathrm{m}$. 
These data suggest that the toxicity of the materials toward PBMCs is dependent on their lateral dimension, the smallest material having a higher impact as compared to the largest one. However, the amino functionalization can totally abolish the observed toxic effects, regardless of the lateral dimension.

\section{A}
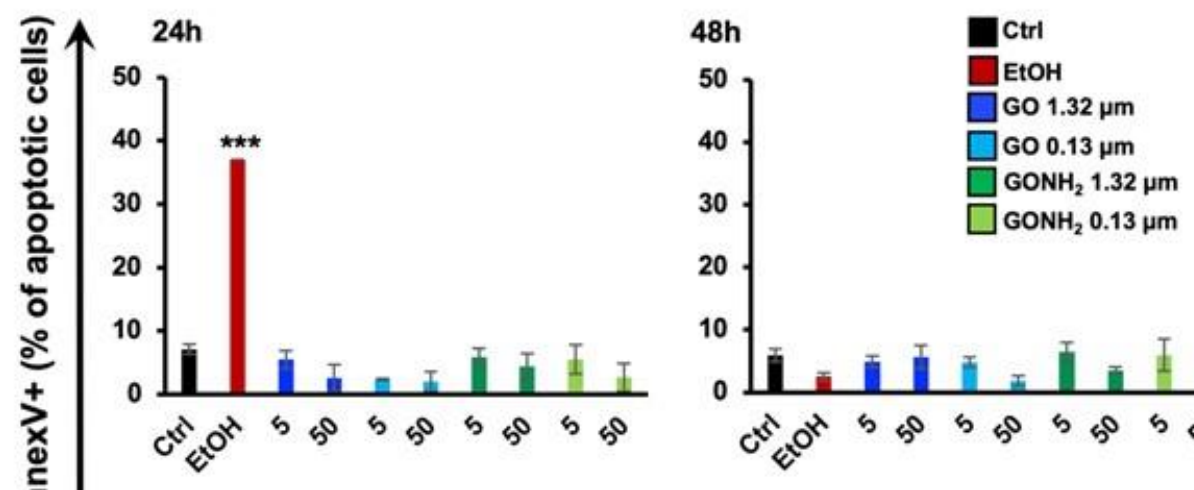

B

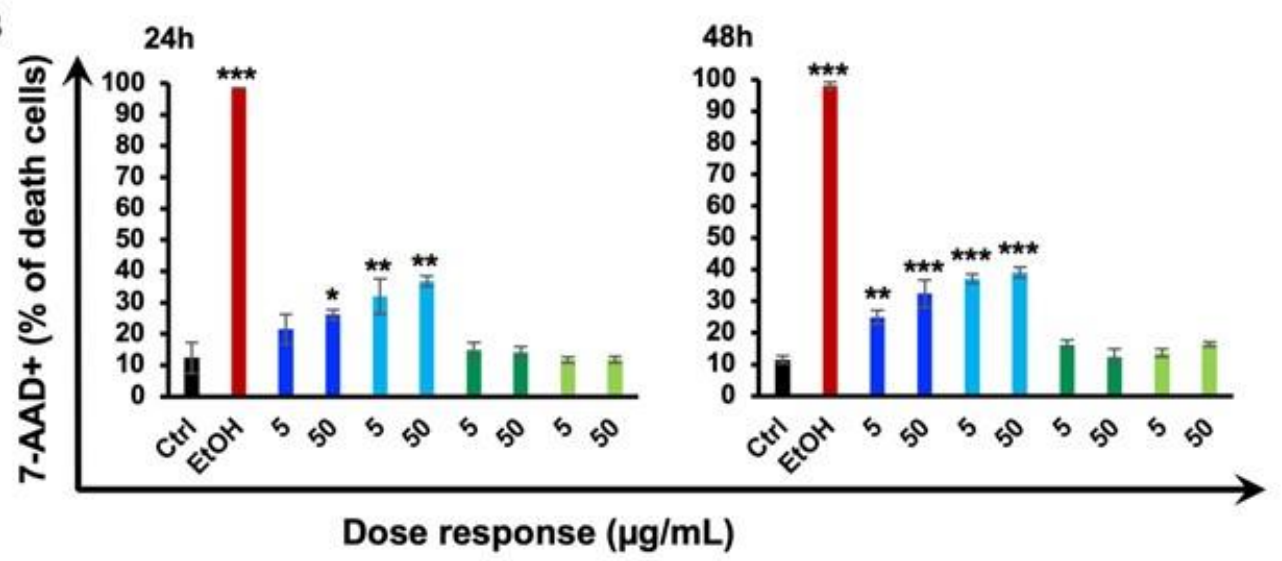

Figure 1. Biocompatibility of GOs with different lateral dimension and functionalization on human PBMCs. PBMCs were incubated with 5 and $50 \mu \mathrm{g} / \mathrm{mL}$ of GO $1.32 \mu \mathrm{m}$, GO $0.13 \mu \mathrm{m}, \mathrm{GONH}_{2} 1.32 \mu \mathrm{m}$ or $\mathrm{GONH}_{2} 0.13 \mu \mathrm{m}$ for 24 and $48 \mathrm{~h}$, or left untreated (Ctrl). Ethanol 70\% (v/v) was used as positive control. The cells were analyzed by FACS Canto II (BD Biosciences). The percentage of apoptotic (A) and necrotic cells (B) was evaluated using Annexin V staining and the amine-reactive dye 7AAD staining, respectively. Data are presented as mean \pm SEM of three independent experiments. Statistical differences: $* p<0.05$; $* *<<0.01$; $* * p<0.001$ (Two-tailed Student's t-test and Anova Tukey's multiple comparison test). 
390

391

392

393

394

395

396

397

398

399

400

401

402

403

404

405

406

407

408

409

410

411

412

413

414

415

416

417

418

419

420

421

We next performed CyTOF high-dimensional screening on human PBMCs to specifically characterize the effects of GOs with different lateral size and functionalization on 13 distinct immune cell subpopulations at the single-cell level. To this end, PBMCs were incubated with $50 \mu \mathrm{g} / \mathrm{mL}$ of GO 1.32 $\mu \mathrm{m}, \mathrm{GO} 0.13 \mu \mathrm{m}, \mathrm{GONH}_{2} 1.32 \mu \mathrm{m}$ or $\mathrm{GONH}_{2} 0.13 \mu \mathrm{m}$ for $24 \mathrm{~h}$, or left untreated (Ctrl).

As previously reported, we used viSNE to reduce the dimensionality of the data set.[37] CD45 ${ }^{+}$events were analyzed by viSNE to cluster all the single-cell events into 9 populations according to 8 protein expression readouts used in the analysis (CD3, CD4, CD8, CD14, CD16, CD20, CD19, and CD123). The viSNE analysis accurately identified helper and cytotoxic $\mathrm{T}$ cells (Th cells and CT cells, respectively), classical (C.), intermediate (Int.) and non-classical (NC) monocytes, myeloid dendritic cells (mDCs), plasmocytoid dendritic cells (pDCs), natural killer cells (NKs) and B cells (Figure 2A). We did not find any significant change in the immune cell cluster morphology induced by the materials (Figure 2B). We than extended our sub-gating analysis to T cell subpopulations, successfully identifying naïve, effector and activated Th and CT cells, applying markers such as CD45RA, CD27, CD38 and HLADR.

Cisplatin (Cis) was used as a marker for viability of all population analyzed. As shown in the heat map (Figure 2C) and histograms (Figure 2D-F), a Cis signal variation was observed in treated cells depending on the material lateral size and functionalization. In fact, although a similar effect exerted by all materials, independently of their features, was observed in all $\mathrm{T}$ cell subpopulations analyzed, representing the most affected subpopulations, other immune cell subsets differentially interacted with the materials. In detail, the material characterized by the smallest lateral dimension (GO $0.13 \mu \mathrm{m})$ was able to induce an overall higher effect on PBMC subpopulations as compared to the largest material GO $1.32 \mu \mathrm{m}$, in particular on NC monocytes, pDCs, NKs and B cells, while the two materials had a similar impact on C. monocytes. In addition, as observed for the flow cytometry analysis, overall the amino functionalization was able to reduce the impact of the materials. In fact, as compared to their pristine counterparts, $\mathrm{GONH}_{2} 1.32 \mu \mathrm{m}$ and $\mathrm{GONH}_{2} 0.13 \mu \mathrm{m}$ had a reduced effect on C. monocytes, NC monocytes, pDCs, B cells and, partially, NKs. Overall, CyTOF findings confirmed the data obtained by the classic flow cytometry method and allowed to evaluate the impact on the different immune subpopulations, revealing the differences among the four materials that were appreciable only by this high-dimensional single-cell technology. The specific effects of the materials on the distinct immune cell subpopulations could be related to the different uptake of the materials in the different typed of cells, as we previously reported for GO into human PBMC subpopulations, enabling the material detection at CyTOF through the functionalization with indium [38]. 
A
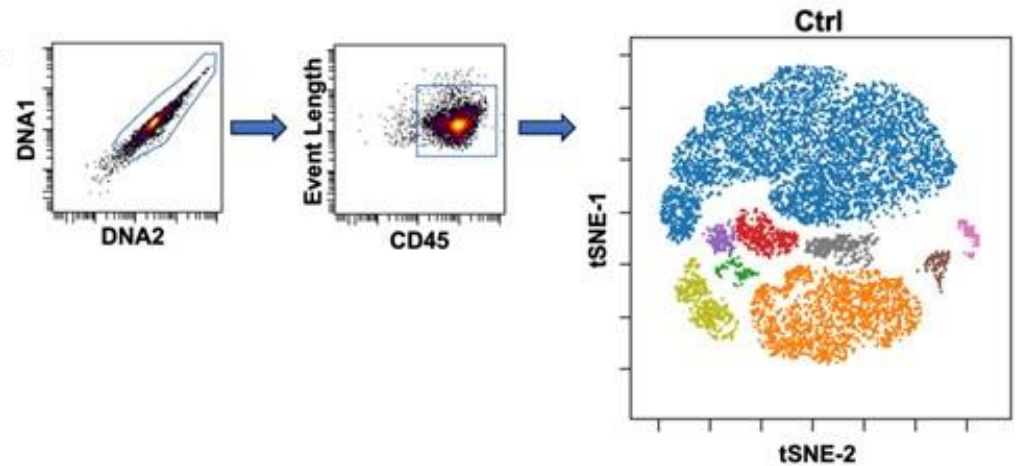

$$
\begin{aligned}
& \square \text { Th. Cells } \\
& \square \text { CT. Cells } \\
& \text { C. Monocytes } \\
& \text { Int. Monocytes } \\
& \square \text { NC. Monocytes } \\
& \text { mDCs }^{\text {mDCs }} \\
& \square \text { NKs } \\
& \square \text { B Cells }
\end{aligned}
$$

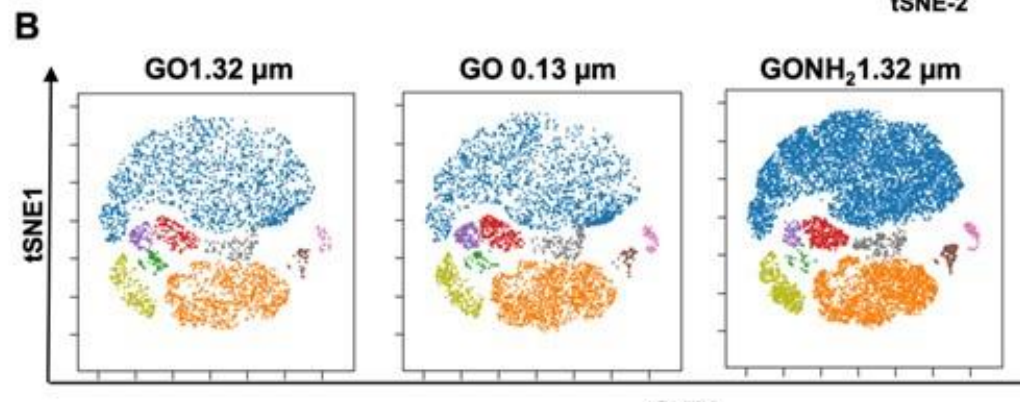

tSNE-2

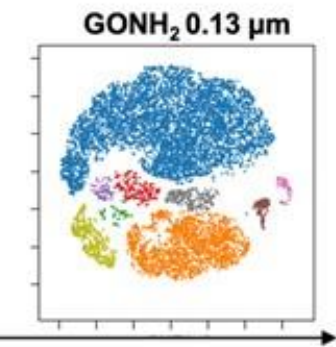

tSNE2

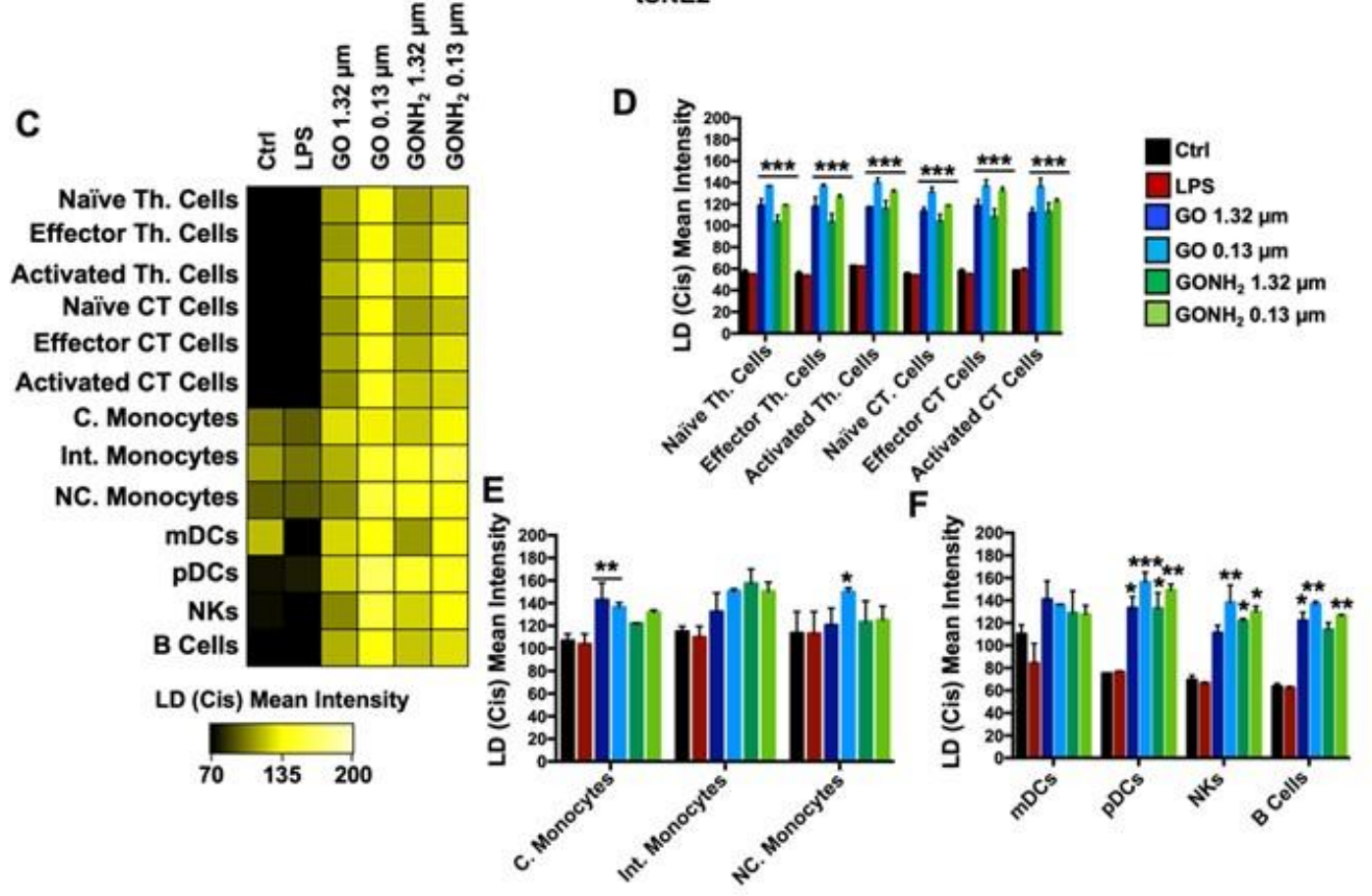

424 Figure 2. Viability on peripheral blood mononuclear cells subpopulations at single cell level. Cell viability analysis using cisplatin (Cis) staining on CyTOF. PBMCs were treated with $50 \mu \mathrm{g} / \mathrm{mL}$ of GO $1.32 \mu \mathrm{m}$, GO $0.13 \mu \mathrm{m}, \mathrm{GONH}_{2} 1.32 \mu \mathrm{m}$ or $\mathrm{GONH}_{2} 0.13 \mu \mathrm{m}$ for $24 \mathrm{~h}$. a) The viSNE analysis report the single-cell subpopulation characterization of PBMCs b) Immune cells cluster morphology after treatment with GOs. c) Heat map and histograms of Cis mean marker expression ratio for all gated immune subpopulations. Histograms of cis mean marker expression ratio for gated d) T cells subpopulations, e) monocytes subpopulations, f) $\mathrm{mDC}, \mathrm{pDC}, \mathrm{NK}$ cell and B cell populations. All the experiments were 
431 performed in triplicate and shown as means \pm SD. $* p<0.05$; $* *<0.01, * * * p<0.001$ by Two-way ANOVA 432 and Tukey's multiple comparison test.

\section{3.4. Changes in the release of TNF- $\alpha$ and the expression of CD25 cell activation marker}

435 Further analyses were carried out to analyze a possible role of the lateral dimension and functionalization 436 of the material on PBMC activation. PBMCs were exposed to GO $1.32 \mu \mathrm{m}, \mathrm{GO} 0.13 \mu \mathrm{m}, \mathrm{GONH}_{2} 1.32$ $437 \mu \mathrm{m}$, or $\mathrm{GONH}_{2} 0.13 \mu \mathrm{m}(50 \mu \mathrm{g} / \mathrm{mL})$ for $24 \mathrm{~h}$ and the production of TNF- $\alpha$ was analyzed by ELISA. 438 Moreover, the expression of the late cell surface activation markers CD25, was evaluated by flow 439 cytometry. LPS $(2 \mu \mathrm{g} / \mathrm{mL})$ was used as a positive control. As shown in Figure 3A, a significant release 440 of TNF- $\alpha$ was observed after exposure to GO $1.32 \mu \mathrm{m}$ and GO $0.13 \mu \mathrm{m}$. In particular, the smallest 441 material (GO $0.13 \mu \mathrm{m})$ was slightly more potent $\left(*^{*} p<0.01\right)$ than GO $1.32 \mu \mathrm{m}\left(*^{*} p<0.05\right)$. The two 442 materials also induced a similar increase in the expression of CD25 $\left({ }^{*} p<0.05\right)$ (Figure 3B). Intriguingly, 443 the amino functionalized materials $\mathrm{GONH}_{2} 1.32 \mu \mathrm{m}$ and $\mathrm{GONH}_{2} 0.13 \mu \mathrm{m}$ did not induce any significant 444 release of TNF- $\alpha$ and any change in CD25 expression (Figure 3A and B), suggesting a lower impact on 445 the modulation of PBMC activation induced by the amino decoration. 


\section{Total PBMCs}

\section{A}

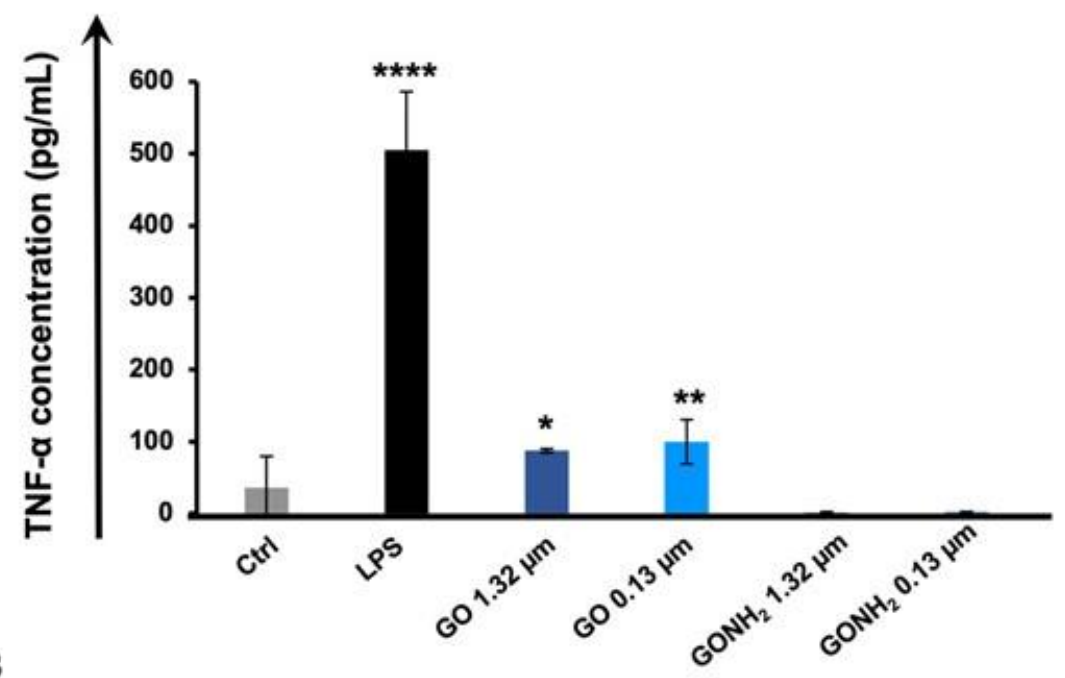

B

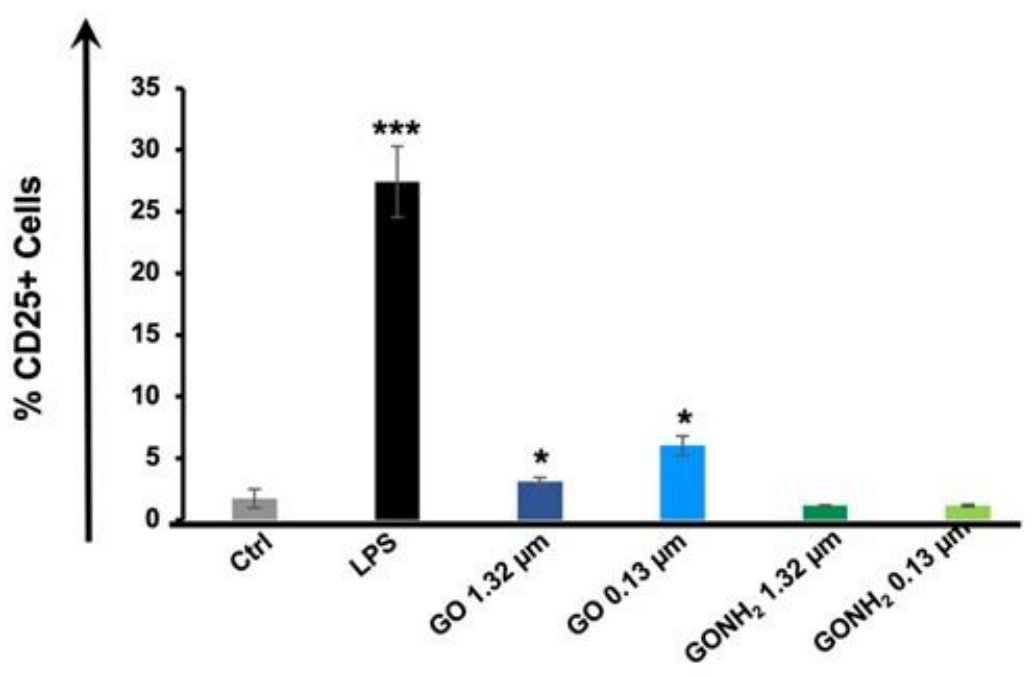

447 Figure 3. Impact of GOs with different later dimensions and functionalization on the expression of 448 CD25 and TNF- $\boldsymbol{\alpha}$. PBMCs were incubated with $50 \mu \mathrm{g} / \mathrm{mL}$ of GO $1.32 \mu \mathrm{m}$, GO $0.13 \mu \mathrm{m}, \mathrm{GONH}_{2}$ $4491.32 \mu \mathrm{m}$ or, $\mathrm{GONH}_{2} 0.13 \mu \mathrm{m}$ for $24 \mathrm{~h}$, or left untreated $(\mathrm{Ctrl})$, and the effects were evaluated on the 450 secretion of TNF- $\alpha$ by ELISA (A). PBMCs were incubated with 5 and $50 \mu \mathrm{g} / \mathrm{mL}$ of GO $1.32 \mu \mathrm{m}$ or GO $4510.13 \mu \mathrm{m}$ for $24 \mathrm{~h}$, or left untreated (Ctrl), and the effects were evaluated on the immune cell activation marker CD25 by FACS Canto II (BD Biosciences). Histograms show the percentage of CD25 cell surface activation marker expression on PBMCs $(\mathbf{B})$. LPS $(2 \mu \mathrm{g} / \mathrm{mL})$ was used as a positive control. Data are presented as mean \pm ST.D. of three independent experiments. Statistical differences: ${ }^{*} p<0.05 ; * * p<0.01$; $* * * p<0.001 ; * * * * p<0.0001$ (One-way Anova and Bonferroni’s post test). 


\subsection{Cytokine and activation marker analysis on distinct immune cell subpopulations by CyTOF}

459

460

461

462

463

464

465

466

467

468

469

470

471

472

473

474

475

476

477

478

479

480

481

482

483

484

485

486

487

488

Further CyTOF analyses were then performed on human PBMCs to specifically characterize the effects on functionality induced by the materials on the 13 distinct immune cell subpopulations. PBMCs were incubated with GO $1.32 \mu \mathrm{m}, \mathrm{GO} 0.13 \mu \mathrm{m}, \mathrm{GONH}_{2} 1.32 \mu \mathrm{m}$ or $\mathrm{GONH}_{2} 0.13 \mu \mathrm{m}(50 \mu \mathrm{g} / \mathrm{mL})$ for $24 \mathrm{~h}$, or left untreated (Ctrl) and single-cell mass cytometry was applied to evaluate the effect at the single-cell level on the release of 7 major cytokines: interleukin (IL)-5, IL-4, IL-2, IL-6, interferon gamma (IFN- $\gamma$ ), macrophage inflammatory proteins (MIP)-1 $\beta$, and tumor necrosis factor (TNF)- $\alpha$. The cytokine release was assessed on naïve CT cells, effector CT cells, activated CT cells, naïve Th cells, effector Th cells, activated Th cells, C. monocytes, Int. monocytes, NC monocytes, mDCs, pDCs, NKs and B cells. LPS $(2 \mu \mathrm{g} / \mathrm{mL})$ was used as a positive control.

The heat map reporting the mean intensity showing the release of cytokines on all the CD45+ PBMC subpopulations suggested that the materials induced an increase of the selected cytokines with different potency. In particular, the largest GO (GO $1.32 \mu \mathrm{m})$ was the most potent material, causing an increase of all the selected cytokines, particularly relevant in monocytes (Figure 4A).

To better highlight the different modulation played by the materials on monocyte subpopulations we report the histograms data analyzed from three donors (Figure 4B) showing the release of monocyte specific cytokines (IL-6, MIP-1 $\beta$, and TNF- $\alpha$ ). While the largest material (GO $1.32 \mu \mathrm{m}$ ) induced IL-6 in all monocyte subpopulations, MIP-1 $\beta$ in C. and NC. monocytes, and TNF- $\alpha$ in Int. monocytes, the smallest GO (GO $0.13 \mu \mathrm{m})$ and both amino functionalized GOs $\left(\mathrm{GONH}_{2} 1.32 \mu \mathrm{m}\right.$ and $\left.\mathrm{GONH}_{2} 0.13 \mu \mathrm{m}\right)$ did not show any significant change in the production of the three cytokines analyzed.

Further activation analyses were performed measuring CD25 (IL-2 receptor alpha, also known as late activation marker), CD80 and HLA-DR expression on all monocyte subpopulations (C., Int., and NC monocytes). As shown in Figure 4C, all the materials were able to change the expression of CD25 and CD80 with different potency in Int. monocytes, while only the non-functionalized materials increased these activation markers also in NC monocyte subpopulation. On the contrary, any significant change was observed for HLA-DR. Overall, single-cell analysis allowed to detect that Int. monocytes are the most modulated population, highly responding to GOs. In detail, all the materials were able to increase the expression of $\mathrm{CD} 25$, with the smallest $\mathrm{GO}(\mathrm{GO} 0.13 \mu \mathrm{m})$ inducing the most pronounced increase of CD25 expression, suggesting that the lateral dimension can be the main factor affecting the activation of this monocytes population. Compared to $\mathrm{GO} 0.13 \mu \mathrm{m}$, its amino functionalized counterpart $\mathrm{GONH}_{2} 0.13$ $\mu \mathrm{m}$ induced a lower increase of CD25 but showed a similar effect on CD80, suggesting that the amino 
functionalization only partially reduces this effect in Int. monocytes. However, the amino 490 functionalization once again proved to be dominant in guiding the immune impact, indeed it totally 491 abolished the ability of the materials to induce the expression of CD80 in NC monocytes. Thus, only 492 pristine GOs and not the amino functionalized materials induced a significant increase of CD80 in NC 493 monocytes.

A

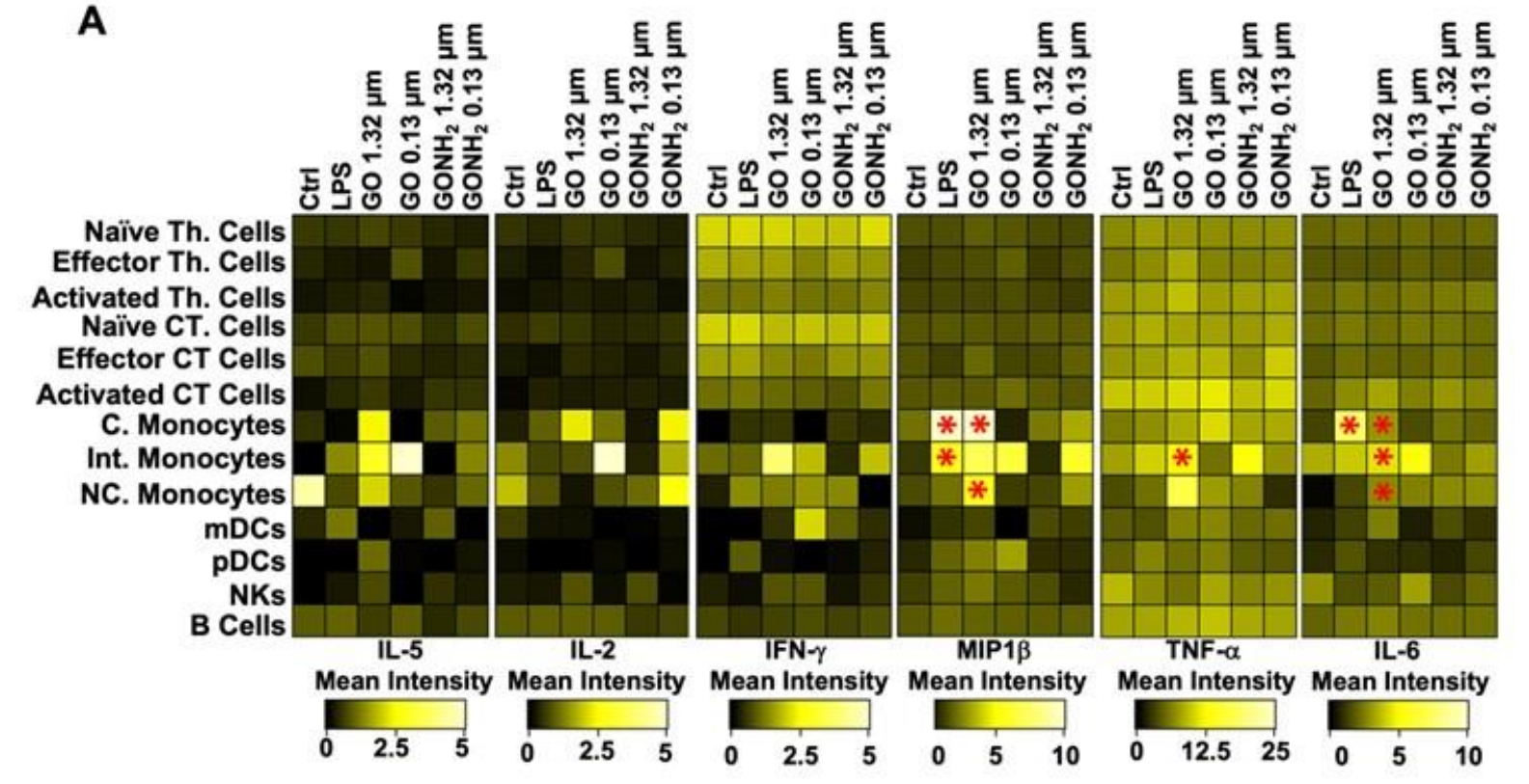

B

C. Monocytes

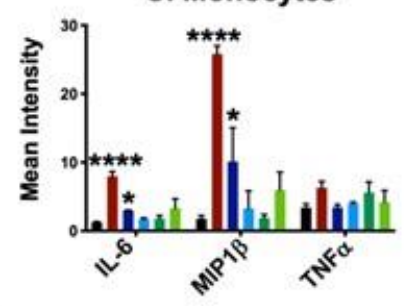

C

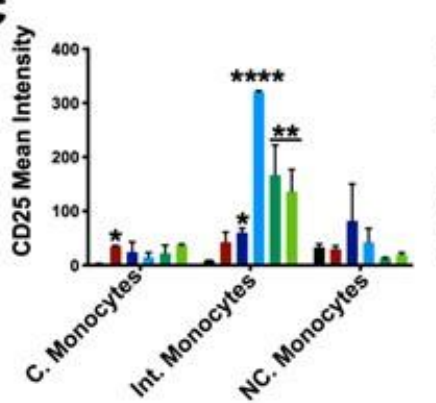

Int. Monocytes
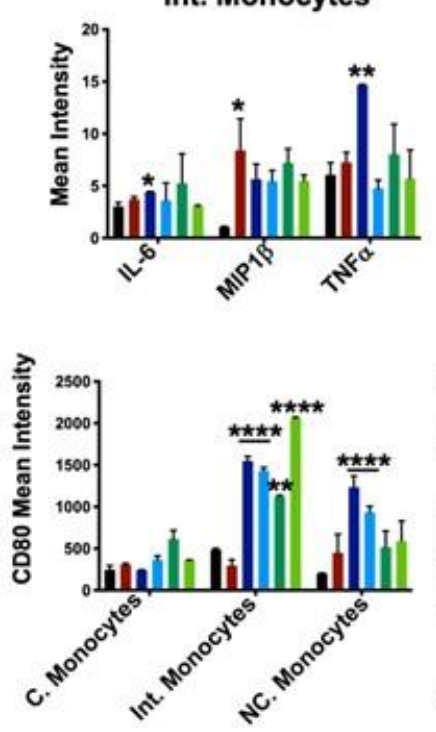

NC. Monocytes
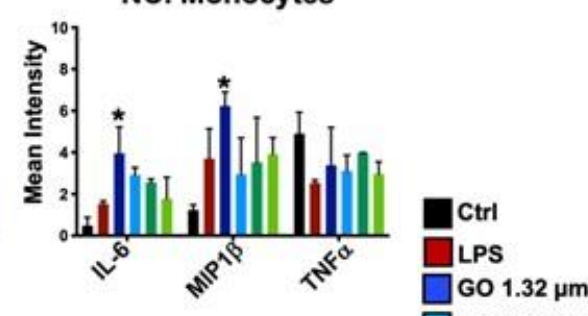

$\square$ Go $0.13 \mu \mathrm{m}$

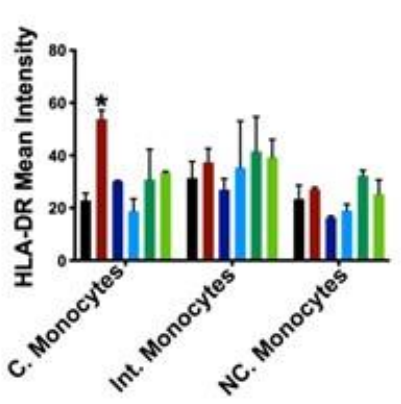


498

499

500

501

502

503

504

505

506

507

508

509

510

511

512

513

514

515

516

517

518

519

520

521

522

523

524

525

526

527

528

529

530

$0.13 \mu \mathrm{m}$ for $24 \mathrm{~h}$, or left untreated (Ctrl) (B). Bar graphs showing monocytes expressing MIP-1b, TNFa, and IL-6 after GO $1.32 \mu \mathrm{m}, \mathrm{GO} 0.13 \mu \mathrm{m}, \mathrm{GONH}_{2} 1.32 \mu \mathrm{m}$ or $\mathrm{GONH}_{2} 0.13 \mu \mathrm{m}$ stimulation. CD14+ CD16- Classical (C.), CD14+ CD16+ Intermediated (Int.) and CD14- CD16+ Non Classical (NC) monocytes are reported. C) CD25, CD80 and HLA-DR activation markers mean intensity on gated monocytes among the three biological replicates. Means \pm SD. Statistical differences: $* p<0.05$; $* * p<0.01 ; * * * p<0.001$ and $* * * * p<0.0001$ (Tow-way ANOVA and Dunnet's multiple comparison tests).

\section{Discussion}

In the last years, graphene has gained considerable attention thanks to its promising applications. Following a possible release in the environment, the biocompatibility of the material is concerned with its interactions with the immune cells found in the blood, representing the first line of defense of our organism against foreign intruders. Using human primary blood immune cells, representing a more closeto-human in vivo condition as compared to cell lines or animal models, we have previously provided evidences that the resulting effects of such interplay are depending on the specific characteristics of the materials.[29, 39-41]

Indeed, it is well-recognized that the different physicochemical properties of GRMs, such as their element composition, functionalization, lateral dimension, number of layers, and starting material used for their production, can modulate their interactions with cells, ultimately influencing their biocompatibility, their downstream effects and, consequently, the possible range of applications.

Among the critical parameters there are the lateral size of the starting material, the absorption capacity, and the possibility of easy functionalization.[27, 42]

In one of the early studies, we have reported that the difference in the size of GO sheets could modulate their impact on primary human and murine macrophages, demonstrating that the smallest material was more effective in affecting cell viability and functionality.[31]

In this context, we recently stressed the knowledge that the lateral dimension could be a predictive criterion for immunotoxicity of 2D materials including GRMs.[43] We showed that mice injected into the peritoneal cavity with small and large lateral size GOs have different ability to recruit and interact with immune cells, i.e. macrophages. We found that the small GO was able to induce a more prominent cell recruitment as a consequence of its greater interaction with peritoneal macrophages, suggesting also a possible higher induction of chemokines following internalization.

The large majority of the studies, such as the above mentioned, were carried out focusing on macrophages as a model for immune response.[44, 45] However, while they are suitable to study the effect of the 
531

532

533

534

535

536

537

538

539

540

541

542

543

544

545

546

547

548

549

550

551

552

553

554

555

556

557

558

559

560

561

562

exposure to nanomaterials assessing acute and chronic inflammation in tissues, they do not represent the ideal model to study the acute immune cell impact after a systemic injection of nanomaterials in the blood stream. Moreover, few data are available on the effects of the different lateral dimension and functionalization of GO on immune cells, only limited to a low number of immune cell types. [17, 22, 46-48] There is still a lack of studies aimed at understanding the structure-activity relationship and the simultaneous evaluation of different physicochemical property effects on the distinct immune cell subpopulations using high-dimensional approaches. This aspect is particularly important from a toxicological point of view, considering that nanoscale materials could easily reach the deeper regions of the lungs, inducing local inflammation and potentially translocating directly into the bloodstream through the pulmonary capillary bed.[18] Consequently, this behavior may directly interact with the blood immune cells and accumulate in other target organs causing systemic inflammation. Therefore, to ensure a safe use of GRMs, there is an urgent need to fill the gap in information to guide the future industrial production.

New single-cell technologies may allow to fill this gap providing insight about the biological impact of nanomaterials with high parameterization.[49-51] Among other technologies, single-cell mass cytometry is the most promising tool for a proper and deep immune characterization of cell response to a wide variety of agents, including GRMs.[29, 52-59] Single-cell mass cytometry employs element-tagged probes that enable the discrimination of particles according to their mass/charge ratio $(\mathrm{m} / \mathrm{z})$ applying the so-called Cytometry by Time-of Flight property, ensuring minimal overlap and background cellular signal.[60] This approach enables high-dimensional cytometry experiments that would not be possible otherwise. The extensive heterogeneity of GRM physicochemical properties such as lateral dimension, and functionalization and the high complexity of the immune system functional response that can differ substantially among cell subpopulations, make them ideal target for single-cell mass cytometry approach. In this view, the present proof-of-concept study shows that CyTOF can help to achieve a thorough and understanding of the effects of the multiple physicochemical characteristics of graphene, at the same time. We focused on the lateral dimension and functionalization as predictive criteria to assess immunotoxicity and immunomodulation of GRMs and 2D materials.

To do so, we performed an integrative characterization of the impact of four GOs different for lateral dimension (GO $1.32 \mu \mathrm{m}$ and $\mathrm{GO} 0.13 \mu \mathrm{m})$ and functionalization $\left(\mathrm{GONH}_{2} 1.32 \mu \mathrm{m}\right.$ and $\left.\mathrm{GONH}_{2} 0.13 \mu \mathrm{m}\right)$. We combined and compared flow cytometry analysis on the unresolved pool of PBMCs and on fifteen immune cell subpopulations detected by single-cell mass cytometry, evaluating the role and possible synergistic effects of the lateral dimension and functionalization on the biocompatibility of the materials. 
563

564

565

566

567

568

569

570

571

572

573

574

575

576

577

578

579

580

581

582

583

584

585

586

587

588

589

590

591

592

593

594

The cell viability experiments showed a significant concentration-dependent viability alteration, involving necrosis or the late stage of apoptosis, exerted with different potency depending on the physicochemical properties of the materials. In particular, the smallest material GO $0.13 \mu \mathrm{m}$ was more effective in decreasing cell viability, suggesting that the toxicity of the materials toward PBMCs is dependent on their lateral dimension. In addition, consistent to our previous study,[31] none of the functionalized materials induced cell toxicity under our treatment conditions, confirming the higher biocompatibility conferred by this specific surface decoration.

The assessment of the viability at the single-cell level confirmed the variation in treated cells, depending on the lateral size and functionalization of the material. Although most of the immune subpopulations analyzed showed a similar interaction with the two pristine materials, compared to the largest GO (GO $1.32 \mu \mathrm{m}$ ), the material characterized by a smallest lateral dimension (GO $0.13 \mu \mathrm{m}$ ) not only evoked a more pronounced effect considering the whole pool of PBMCs but also showed an equal or higher impact towards all the distinct immune cell subpopulations analyzed. In particular, a higher impact of GO 0.13 $\mu \mathrm{m}$, compared to GO $1.32 \mu \mathrm{m}$, was observed in NC monocytes, pDCs, NK cells and B cells, corroborating the hypothesis that the toxicity of the materials toward PBMCs is dependent on their lateral dimension. The functionalized $\mathrm{GONH}_{2} 1.32 \mu \mathrm{m}$, and $\mathrm{GONH}_{2} 0.13 \mu \mathrm{m}$ exerted reduced toxicity, especially in $\mathrm{C}$. and $\mathrm{NC}$ monocytes, confirming that functionalization helps in reducing the toxic effect played by pristine GO, as we previously shown. ${ }^{29}$

Subsequently, the immune functional response induced by the four GOs on the bulk PBMCs was analyzed, showing a similar ability of the non-functionalized GOs to elicit the expression of TNF- $\alpha$ and the activation marker CD25 (IL-2 receptor alpha, also known as late activation marker), not exerted by the functionalized materials.

Single-cell analysis revealed the interaction of all GOs with the immune cells. Surprisingly, the largest material (GO $1.32 \mu \mathrm{m})$ induced an overall higher increase in the release of the selected cytokines, particularly relevant in monocyte subpopulations and plasma B cells. The impact of the material on monocytes is of particular interest, since this population, together with macrophages and dendritic cells, plays an important role in both the innate and adaptive immunity, by exerting immune-regulatory proprieties triggering the production of several modulatory cytokines.[61] Therefore, further analyses were carried out on monocytes, being the cells highly modulated in our screening. Unpredictably, the largest material (GO $1.32 \mu \mathrm{m})$ exerted the highest effect, inducing a more prominent expression of monocyte-specific cytokines (MIP-1 $\beta$, TNF- $\alpha$, and IL-6) compared to GO $0.13 \mu \mathrm{m}$, in particular in classical monocytes and intermediated monocyte subpopulations. Our results, in line with previous 
595

596

597

598

599

600

601

602

603

604

605

606

607

608

609

610

611

612

613

614

615

616

617

618

619

620

621

622

623

624

625

626

findings showing that GO with larger lateral size induced an increase of MIP-1 $\beta$, TNF- $\alpha$, IL-6 and other inflammatory mediators in macrophages,[45] allowed to broaden the knowledge concerning the specific impact on the different monocyte subpopulations.

In addition, the analysis of the activation marker CD25 confirmed that C. monocytes and Int. monocytes were the main monocyte subpopulations affected by the materials, while CD80 was specifically modulated by both $\mathrm{GO} 1.32 \mu \mathrm{m}$, and $\mathrm{GO} 0.13 \mu \mathrm{m}$ in $\mathrm{NC}$ monocytes. Intriguingly, the functionalization significantly decreased the effect played by the lateral dimension dampening GO effects on monocytes. Overall, our findings suggest a role for the lateral dimension on the material impact on immune cell viability, and activation revealing that GO of smaller lateral size is able to significantly affect cell viability in several immune cell subpopulations. On the contrary, we found the ability of the largest GO to induce a higher activation response on monocytes. These data are in line with previous studies reporting that, compared to small GO, large GO showed lesser toxicity but stronger absorption onto the plasma membrane of macrophages, enhancing the production of cytokines and promoting proinflammatory pathways and M1 polarization.[44]

\section{Conclusions}

Graphene is booming in its large-scale production and is part of our everyday life, as happened for plastics about 50 years ago. After 50 years, we just started to pose the question of what polymers in plastic products are more toxic for the health of living organisms. What if the production of plastic was based on its particular toxicological profile and guided by its chemical-physical characteristics? The present study poses the same question for $\mathrm{GO}$, a material that is exponentially growing in its production in the last years. Aiming at guiding its production based on the chemical, physical and toxicological profiling, we considered here two key parameters at the same time: lateral dimension and surface functionalization. These characteristics were never investigated at the same time and we added them on a scale to understand if one of them was a prevalent parameter or if they could act synergistically. The immune system will be the first barrier for any type of exposure to GRMs, we therefore employed the most versatile and powerful strategy in this context: single-cell mass cytometry.

Our finding revealed the specific higher impact of the small lateral dimension of GO on a total of 15 different immune subpopulations in relation to viability and functionality. We discovered that the aminofunctionalization of the GOs surface is a dominant factor upon lateral dimension and it ameliorates the biocompatibility, and immune activation, decreasing or undoing the effects played by the material size. 
627 Moreover, by the comparison among flow cytometry data and single-cell mass cytometry data we 628 demonstrate that data implementation based on high-dimensional deep phenotyping technologies is a 629 critical aspect to uncover the real interactions between nanomaterials and a wide variety of cell types. 630 The specific behavior of GO with the distinct immune cell subpopulations depending on the 631 functionalization and lateral dimension should be taken into consideration for the future exploration of GO applications, its consequent exposure and potential toxicity.

633

634

635

636

637

638

639

640

641

642

643

644

645

646

647

648

649

650

651

652

653

654

655

656

657

658

659

\section{Conflict of Interest}

All the authors declare no conflict of interests.

\section{Author Contributions}

L.G.D. conceived the idea and supervised the work. L.F., and M.O. implemented the experiments with help from G.R., V.B., C.F., C.G., and A.Y. A. B. E.T, and V.P. designed and characterized the nanomaterials. G.C. supported the Single Cell experiments. L.F., M.O, and L.G.D. wrote the manuscript with contributions from all authors.

\section{Acknowledgments}

This work was partly supported by the European Union's Horizon 2020 research and innovation programme under the Marie Sklodowska-Curie grant agreement no. 734381 (CARBO-IMmap), and FLAGERA JTC Graphene 2015 (G-IMMUNOMICS project), and the Agence Nationale de la Recherche (ANR) through the LabEx project Chemistry of Complex Systems (ANR-10-LABX-0026_CSC). The authors gratefully acknowledge the financial support from the EU GRAPHENE Flagship project (no. 785219). The authors wish to thank T. Wang for his help on zeta potential measurements, I. A. Vacchi for the contribution to XPS analyses, C. Royer and V. Demais for TEM analyses at the Plateforme Imagerie in Vitro at the INCI (Strasbourg, France).

\section{References}

[1] T. Kuila, S. Bose, A.K. Mishra, P. Khanra, N.H. Kim, J.H. Lee, Prog Mater Sci, 57 (2012) 10611105.

[2] S. Park, R.S. Ruoff, Nat Nanotechnol, 4 (2009) 217-224.

[3] S. Mao, H.H. Pu, J.H. Chen, Rsc Adv, 2 (2012) 2643-2662.

[4] X.F. Gao, J. Jang, S. Nagase, J Phys Chem C, 114 (2010) 832-842. 
660 [5] D.W. Boukhvalov, M.I. Katsnelson, J Phys-Condens Mat, 21 (2009).

661 [6] D.K. James, J.M. Tour, Accounts of chemical research, 46 (2013) 2307-2318.

662 [7] P. Kumar, B. Das, B. Chitara, K.S. Subrahmanyam, K. Gopalakrishnan, S.B. Krupanidhi, C.N.R.

663 Rao, Macromol Chem Phys, 213 (2012) 1146-1163.

664 [8] H.X. Chang, H.K. Wu, Energ Environ Sci, 6 (2013) 3483-3507.

665 [9] K. Yang, L.Z. Feng, H. Hong, W.B. Cai, Z. Liu, Nat Protoc, 8 (2013) 2392-2403.

666 [10] M. Quintana, E. Vazquez, M. Prato, Acc Chem Res, 46 (2013) 138-148.

667 [11] J. Kim, J. Lee, D. Son, M.K. Choi, D.H. Kim, Nano Converg, 3 (2016) 4.

668 [12] S.R. Shin, Y.C. Li, H.L. Jang, P. Khoshakhlagh, M. Akbari, A. Nasajpour, Y.S. Zhang, A.

669 Tamayol, A. Khademhosseini, Adv Drug Deliv Rev, 105 (2016) 255-274.

670 [13] D.P. Singh, C.E. Herrera, B. Singh, S. Singh, R.K. Singh, R. Kumar, Mater Sci Eng C Mater Biol 671 Appl, 86 (2018) 173-197.

672 [14] J. Lee, J. Kim, S. Kim, D.H. Min, Adv Drug Deliv Rev, 105 (2016) 275-287.

673 [15] M.V.D.Z. Park, E.A.J. Bleeker, W. Brand, F.R. Cassee, M. van Elk, I. Gosens, W.H. de Jong, 674 J.A.J. Meesters, W.J.G.M. Peijnenburg, J.T.K. Quik, R.J. Vandebriel, A.J.A.M. Sips, ACS Nano, 11 675 (2017) 9574-9593.

676 [16] F. Cavion, L. Fusco, S. Sosa, C. Manfrin, B. Alonso, A. Zurutuza, R. Della Loggia, A. Tubaro, M. 677 Prato, M. Pelin, Environmental Science: Nano, 7 (2020) 3605-3615.

678 [17] B. Fadeel, C. Bussy, S. Merino, E. Vázquez, E. Flahaut, F. Mouchet, L. Evariste, L. Gauthier, A.J. 679 Koivisto, U. Vogel, C. Martín, L.G. Delogu, T. Buerki-Thurnherr, P. Wick, D. Beloin-Saint-Pierre, R. 680 Hischier, M. Pelin, F. Candotto Carniel, M. Tretiach, F. Cesca, F. Benfenati, D. Scaini, L. Ballerini, K. 681 Kostarelos, M. Prato, A. Bianco, ACS Nano, 12 (2018) 10582-10620.

682 [18] B. Li, J. Yang, Q. Huang, Y. Zhang, C. Peng, Y. Zhang, Y. He, J. Shi, W. Li, J. Hu, C. Fan, Npg 683 Asia Materials, 5 (2013) e44.

684 [19] D. Zhang, Z. Zhang, Y. Liu, M. Chu, C. Yang, W. Li, Y. Shao, Y. Yue, R. Xu, Biomaterials, 68 685 (2015) 100-113.

686 [20] G. Qu, X. Wang, Q. Liu, R. Liu, N. Yin, J. Ma, L. Chen, J. He, S. Liu, G. Jiang, J Environ Sci 687 (China), 25 (2013) 873-881.

688 [21] A. Gazzi, L. Fusco, M. Orecchioni, S. Ferrari, G. Franzoni, J.S. Yan, M. Rieckher, G. Peng, M.A. 689 Lucherelli, I.A. Vacchi, N.D.Q. Chau, A. Criado, A. Istif, D. Mancino, A. Dominguez, H. Eckert, E. 690 Vázquez, T.D. Ros, P. Nicolussi, V. Palermo, B. Schumacher, G. Cuniberti, Y. Mai, C. Clementi, M. 691 Pasquali, X. Feng, K. Kostarelos, A. Yilmazer, D. Bedognetti, B. Fadeel, M. Prato, A. Bianco, L.G. 692 Delogu, Journal of Physics: Materials, 3 (2020) 034009.

693 [22] M. Orecchioni, C. Menard-Moyon, L.G. Delogu, A. Bianco, Adv Drug Deliv Rev, 105 (2016) $694 \quad 163-175$.

695 [23] C. Kinnear, T.L. Moore, L. Rodriguez-Lorenzo, B. Rothen-Rutishauser, A. Petri-Fink, Chem Rev, 696117 (2017) 11476-11521.

697 [24] S. Kumar, S.H. Parekh, Communications Chemistry, 3 (2020) 8.

698 [25] R. Toy, P.M. Peiris, K.B. Ghaghada, E. Karathanasis, Nanomedicine (Lond), 9 (2014) 121-134.

699 [26] M. Zhu, G. Nie, H. Meng, T. Xia, A. Nel, Y. Zhao, Accounts of Chemical Research, 46 (2013)

700

701

702

703

704

705 622-631.

[27] P. Wick, A.E. Louw-Gaume, M. Kucki, H.F. Krug, K. Kostarelos, B. Fadeel, K.A. Dawson, A. Salvati, E. Vazquez, L. Ballerini, M. Tretiach, F. Benfenati, E. Flahaut, L. Gauthier, M. Prato, A. Bianco, Angew Chem Int Ed Engl, 53 (2014) 7714-7718.

[28] V. Castagnola, J. Cookman, J.M. de Araújo, E. Polo, Q. Cai, C.P. Silveira, Ž. Krpetić, Y. Yan, L. Boselli, K.A. Dawson, Nanoscale Horizons, 2 (2017) 187-198. 
706

707

708

709

710

711

712

713

714

715

716

717

718

719

720

721

722

723

724

725

726

727

728

729

730

731

732

733

734

735

736

737

738

739

740

741

742

743

744

745

746

747

748

749

750

751

752

[29] M. Orecchioni, D. Bedognetti, L. Newman, C. Fuoco, F. Spada, W. Hendrickx, F.M. Marincola, F. Sgarrella, A.F. Rodrigues, C. Menard-Moyon, G. Cesareni, K. Kostarelos, A. Bianco, L.G. Delogu, Nat Commun, 8 (2017) 1109.

[30] B. Fadeel, C. Bussy, S. Merino, E. Vazquez, E. Flahaut, F. Mouchet, L. Evariste, L. Gauthier, A.J. Koivisto, U. Vogel, C. Martin, L.G. Delogu, T. Buerki-Thurnherr, P. Wick, D. Beloin-Saint-Pierre, R. Hischier, M. Pelin, F. Candotto Carniel, M. Tretiach, F. Cesca, F. Benfenati, D. Scaini, L. Ballerini, K. Kostarelos, M. Prato, A. Bianco, ACS Nano, 12 (2018) 10582-10620.

[31] J. Russier, E. Treossi, A. Scarsi, F. Perrozzi, H. Dumortier, L. Ottaviano, M. Meneghetti, V. Palermo, A. Bianco, Nanoscale, 5 (2013) 11234-11247.

[32] E. Treossi, M. Melucci, A. Liscio, M. Gazzano, P. Samorì, V. Palermo, Journal of the American Chemical Society, 131 (2009) 15576-15577.

[33] S.P. Mukherjee, N. Lozano, M. Kucki, A.E. Del Rio-Castillo, L. Newman, E. Vazquez, K.

Kostarelos, P. Wick, B. Fadeel, PLoS One, 11 (2016) e0166816.

[34] S.C. Bendall, E.F. Simonds, P. Qiu, A.D. Amir el, P.O. Krutzik, R. Finck, R.V. Bruggner, R.

Melamed, A. Trejo, O.I. Ornatsky, R.S. Balderas, S.K. Plevritis, K. Sachs, D. Pe'er, S.D. Tanner, G.P. Nolan, Science, 332 (2011) 687-696.

[35] G.R. Ngoc Do Quyen Chau, Jésus Raya, Isabella Anna Vacchi, Cécilia Ménard-Moyon, Yuta Nishina, Alberto Bianco, Carbon, 122 (2017) 643-652.

[36] G. Reina, A. Ruiz, D. Murera, Y. Nishina, A. Bianco, ACS Appl Mater Interfaces, 11 (2019) 7695-7702.

[37] A.D. Amir el, K.L. Davis, M.D. Tadmor, E.F. Simonds, J.H. Levine, S.C. Bendall, D.K. Shenfeld, S. Krishnaswamy, G.P. Nolan, D. Pe'er, Nat Biotechnol, 31 (2013) 545-552.

[38] M. Orecchioni, V. Bordoni, C. Fuoco, G. Reina, H. Lin, M. Zoccheddu, A. Yilmazer, B. Zavan, G. Cesareni, D. Bedognetti, A. Bianco, L.G. Delogu, Small, 16 (2020) e2000123.

[39] L. Fusco, E. Avitabile, V. Armuzza, M. Orecchioni, A. Istif, D. Bedognetti, T. Da Ros, L.G.

Delogu, Carbon, 160 (2020) 390-404.

[40] M. Orecchioni, D.A. Jasim, M. Pescatori, R. Manetti, C. Fozza, F. Sgarrella, D. Bedognetti, A. Bianco, K. Kostarelos, L.G. Delogu, Adv Healthc Mater, 5 (2016) 276-287.

[41] M. Pescatori, D. Bedognetti, E. Venturelli, C. Menard-Moyon, C. Bernardini, E. Muresu, A. Piana, G. Maida, R. Manetti, F. Sgarrella, A. Bianco, L.G. Delogu, Biomaterials, 34 (2013) 4395-4403.

[42] K. Bhattacharya, S.P. Mukherjee, A. Gallud, S.C. Burkert, S. Bistarelli, S. Bellucci, M. Bottini, A. Star, B. Fadeel, Nanomedicine, 12 (2016) 333-351.

[43] A.F. Rodrigues, L. Newman, D.A. Jasim, I.A. Vacchi, C. Menard-Moyon, L.E. Crica, A. Bianco, K. Kostarelos, C. Bussy, Arch Toxicol, 92 (2018) 3359-3379.

[44] J. Ma, R. Liu, X. Wang, Q. Liu, Y. Chen, R.P. Valle, Y.Y. Zuo, T. Xia, S. Liu, ACS Nano, 9

(2015) 10498-10515.

[45] H. Yue, W. Wei, Z. Yue, B. Wang, N. Luo, Y. Gao, D. Ma, G. Ma, Z. Su, Biomaterials, 33 (2012) 4013-4021.

[46] A. Gazzi, L. Fusco, A. Khan, D. Bedognetti, B. Zavan, F. Vitale, A. Yilmazer, L.G. Delogu, Front Bioeng Biotechnol, 7 (2019) 295.

[47] M. Orecchioni, R. Cabizza, A. Bianco, L.G. Delogu, Theranostics, 5 (2015) 710-723.

[48] L. Fusco, A. Gazzi, G. Peng, Y. Shin, S. Vranic, D. Bedognetti, F. Vitale, A. Yilmazer, X. Feng,

B. Fadeel, C. Casiraghi, L.G. Delogu, Theranostics, 10 (2020) 5435-5488.

[49] E. Galli, E. Friebel, F. Ingelfinger, S. Unger, N.G. Núñez, B. Becher, European Journal of Immunology, 49 (2019) 212-220.

[50] Matthew H. Spitzer, Garry P. Nolan, Cell, 165 (2016) 780-791.

[51] D.J. Kunz, T. Gomes, K.R. James, Frontiers in Immunology, 9 (2018). 
[52] Y.-S.S. Yang, P.U. Atukorale, K.D. Moynihan, A. Bekdemir, K. Rakhra, L. Tang, F. Stellacci, D.J. Irvine, Nature Communications, 8 (2017) 14069. [53] Z. Good, L. Borges, N. Vivanco Gonzalez, B. Sahaf, N. Samusik, R. Tibshirani, G.P. Nolan, S.C. Bendall, Nat Biotechnol, 37 (2019) 259-266.

[54] S.P. Rosshart, J. Herz, B.G. Vassallo, A. Hunter, M.K. Wall, J.H. Badger, J.A. McCulloch, D.G. Anastasakis, A.A. Sarshad, I. Leonardi, N. Collins, J.A. Blatter, S.J. Han, S. Tamoutounour, S. Potapova, M.B. Foster St Claire, W. Yuan, S.K. Sen, M.S. Dreier, B. Hild, M. Hafner, D. Wang, I.D. Iliev, Y. Belkaid, G. Trinchieri, B. Rehermann, Science, 365 (2019).

[55] B.J. Stewart, J.R. Ferdinand, M.D. Young, T.J. Mitchell, K.W. Loudon, A.M. Riding, N. Richoz, G.L. Frazer, J.U.L. Staniforth, F.A. Vieira Braga, R.A. Botting, D.M. Popescu, R. Vento-Tormo, E. Stephenson, A. Cagan, S.J. Farndon, K. Polanski, M. Efremova, K. Green, M. Del Castillo VelascoHerrera, C. Guzzo, G. Collord, L. Mamanova, T. Aho, J.N. Armitage, A.C.P. Riddick, I. Mushtaq, S. Farrell, D. Rampling, J. Nicholson, A. Filby, J. Burge, S. Lisgo, S. Lindsay, M. Bajenoff, A.Y. Warren, G.D. Stewart, N. Sebire, N. Coleman, M. Haniffa, S.A. Teichmann, S. Behjati, M.R. Clatworthy, Science, 365 (2019) 1461-1466.

[56] A. Alpert, Y. Pickman, M. Leipold, Y. Rosenberg-Hasson, X. Ji, R. Gaujoux, H. Rabani, E. Starosvetsky, K. Kveler, S. Schaffert, D. Furman, O. Caspi, U. Rosenschein, P. Khatri, C.L. Dekker, H.T. Maecker, M.M. Davis, S.S. Shen-Orr, Nat Med, 25 (2019) 487-495. [57] M. Cella, R. Gamini, C. Secca, P.L. Collins, S. Zhao, V. Peng, M.L. Robinette, J. Schettini, K. Zaitsev, W. Gordon, J.K. Bando, K. Yomogida, V. Cortez, C. Fronick, R. Fulton, L.L. Lin, S. Gilfillan, R.A. Flavell, L. Shan, M.N. Artyomov, M. Bowman, E.M. Oltz, S.A. Jelinsky, M. Colonna, Nat Immunol, 20 (2019) 980-991.

[58] C. Bottcher, S. Schlickeiser, M.A.M. Sneeboer, D. Kunkel, A. Knop, E. Paza, P. Fidzinski, L. Kraus, G.J.L. Snijders, R.S. Kahn, A.R. Schulz, H.E. Mei, N.B.B. Psy, E.M. Hol, B. Siegmund, R. Glauben, E.J. Spruth, L.D. de Witte, J. Priller, Nat Neurosci, 22 (2019) 78-90. [59] E. Becht, L. McInnes, J. Healy, C.A. Dutertre, I.W.H. Kwok, L.G. Ng, F. Ginhoux, E.W. Newell, Nat Biotechnol, (2018). [60] D.R. Bandura, V.I. Baranov, O.I. Ornatsky, A. Antonov, R. Kinach, X. Lou, S. Pavlov, S. Vorobiev, J.E. Dick, S.D. Tanner, Analytical Chemistry, 81 (2009) 6813-6822. [61] D.C. Dale, L. Boxer, W.C. Liles, Blood, 112 (2008) 935-945. 